\title{
Nanotherapy for Early Dementia: Targeting Senile Endothelium
}

\author{
Joseph S. D'Arrigo, Ph.D. \\ Cavitation-Control Technology Inc., Farmington, CT 06032, USA
}

Present address: Cav-Con Inc., 15214 NE 8th Street, Unit G-29, Bellevue, WA 98007, USA

Tel: $425-653-3108$

E-mail: cavcon@ntplx.net

\begin{abstract}
Due to the complexity of Alzheimer's disease, multiple cellular types need to be targeted simultaneously in order for a given therapy to demonstrate any major effectiveness. Ultrasound-sensitive coated microbubbles (in a targeted lipid nanoemulsion) are available. Versatile small molecule drug(s) targeting multiple pathways of Alzheimer's disease pathogenesis are known. By incorporating such drug(s) into the targeted LCM/ND lipid nanoemulsion type, one obtains a multitasking combination therapeutic for translational medicine. This multitasking therapeutic targets cell-surface scavenger receptors (mainly SRBI), making possible for various Alzheimer's-related cell types to be simultaneously searched out for localized drug treatment in vivo. Besides targeting cell-surface SR-BI, the proposed LCM/ND-nanoemulsion combination therapeutic(s) include a characteristic lipid-coated microbubble [LCM] subpopulation (i.e., a stable LCM suspension); such film-stabilized microbubbles are well known to substantially reduce the acoustic power levels needed for accomplishing temporary noninvasive (transcranial) ultrasound treatment, or sonoporation, if additionally desired for the Alzheimer's patient.
\end{abstract}

\section{Key Words:}

Alzheimer's-disease; dementia; drug targeting; nanoemulsion; neuroinflammation; oxidative stress; scavenger receptors; sonoporation; transcranial ultrasound 


\section{Background}

Vascular brain lesions are very common in people over 70 years old, and a large proportion of dementia cases may be attributable to cerebrovascular disease. Small-vessel disease is commonly found in patients who have other brain pathologies, such as the plaques and tangles associated with neurodegenerative disease; small-vessel disease also increases the risk of Alzheimer's disease. In fact, vascular cognitive impairment and dementia (VCID) is the second leading cause of dementia behind Alzheimer's disease, and is a frequent comorbidity in the Alzheimer's patient (Cooper and Mitchell 2016; Dichgans and Leys 2017; Greenberg et al. [for MarkVCID consortium] 2017; Kalaria 2016; Perrotta et al. 2016; Sudduth et al. 2017). On a worldwide basis, 36 million people had dementia in 2010; of these dementia patients, 60\%-80\% have Alzheimer's disease (Bhat et al. 2015; Dichgans and Leys 2017; Manukhina et al. 2016).

\section{Transcranial Ultrasound}

The recent preclinical report of using transcranial ultrasound to clear out amyloid- $\beta$ plaques (Leinenga and Gotz 2015) in mouse brain is quite intriguing, but a related technical news report (Torrice 2015) questions whether this method can work in people without causing damage. Alzheimer's patients already have disrupted blood-brain barriers, so that any interaction of microbubbles (acoustically activated by ultrasound) with the blood-brain barrier (BBB) needs to be done very carefully so as not to make matters worse for the Alzheimer's patient (Torrice 2015). This expressed caution also has relevance to a recent review concerning therapies for Alzheimer's disease (Franco and Cedazo-Minguez 2014). The authors summarize the field by emphasizing that many of the therapeutic strategies tested (in animal models) have been successful, but none in humans. There is a striking deficit in translational research, i.e., to take a successful treatment in mice and translate it to the Alzheimer's patient. The authors assert that either the rodent models are not good, or we should extract only the most useful information from those animal models (Franco and Cedazo-Minguez 2014). In view of all the foregoing arguments, it appears likely that intravenous injection of film-stabilized microbubbles is quite useful since such preformed microbubbles are well known to substantially reduce the acoustic power levels needed for temporary noninvasive (transcranial) ultrasound opening of the BBB (Bing et al. 2014; Lammers et al. 2015; Marquet et al. 2011), that is, for accomplishing "sonoporation".

\section{Sonoporation}

The structural mechanism for sonoporation by microbubbles/nanobubbles has very recently been studied (Goliaei et al. 2015) in more detail by performing molecular dynamics computer simulations on systems that contained a model of the tight junctions from the BBB. When no bubble is present in the system, no damage to the model tight junction is observed when the traveling shock (or sonic) wave propagates across it. However, in the presence of a nanobubble, even when the impulse of the shock wave is relatively low, the implosion of the nanobubble causes significant structural change to their model tight junction (Goliaei et al. 
2015). These investigators further explain the structural mechanism of (lipid-bilayer) membrane poration, from shock wave (or sonic wave) induced nanobubble collapse, through the use of (course-grain) molecular dynamics simulations. Specifically, in the absence of a nanobubble, shock pressure is evenly distributed along the lateral area of the (modeled lipidbilayer) membrane; whereas in the presence of a nanobubble an unequal distribution of pressure on the membrane is created, leading to the membrane poration (Adhikari et al. 2015).

\section{Receptor-Mediated Drug Delivery for Alzheimer's Disease}

Moreover, by appropriate choice of film-stabilized microbubbles that can also carry a suitable drug across the BBB for localized delivery, it may be possible for the ultrasound intensity (acoustic power level) to be lowered even further -- resulting in even smaller chances of doing any harm to brain tissue in the patient. In actuality, various types of film-stabilized microbubble agent exist which can function as a drug carrier. However, many of these preformed microbubble agents are incapable, after intravenous injection, of targeting any localized tissue sites or specific lesions. While some of the remaining film-stabilized microbubble agents are capable of targeting, very few appear capable of searching out the appropriate (cell-surface) receptors lining the vasculature of the human brain or within Alzheimer's disease sites in actual patients. Those Alzheimer's-disease-related human receptors involve certain "lipoprotein receptors", including notably the (class B) scavenger receptor referred to as SR-BI (D'Arrigo 2011) which has been found to display significantly impaired function in Alzheimer's patients (Kahlil et al. 2012). In this study of humans -where, as in mice (Thanopoulou et al. 2010), SR-BI is well established as a major highdensity lipoprotein (HDL) receptor -- HDL were isolated from 20 healthy subjects and from 39 Alzheimer's patients. The anti-inflammatory activity of HDL was found to be significantly lower in Alzheimer's patients, which paralleled additional results revealing that Alzheimer's disease had impaired the interaction of HDL with SR-BI receptors obtained from these patients. The authors conclude that their study, using humans, provides evidence for the first time that the functionality of HDL is impaired in Alzheimer's disease, and that this alteration might be caused by Alzheimer's-disease-associated oxidative stress and inflammation (Kahlil et al. 2012). More recently, Song et al. (2015) have similarly showed that the antiinflammatory effects of HDL are dependent on SR-BI expression on macrophages (a type of immune cell). These investigators point out that besides HDL's role in regulating cholesterol metabolism, HDL has been shown to exhibit antioxidant and anti-inflammatory effects in the vasculature (Song et al. 2015). To now summarize the various cell types which all display cell-surface SR-BI and are potentially implicated in Alzheimer's disease, the report by Thanopoulou et al. (2010) should next be considered. These authors point out that SR-BI has been identified on astrocytes and vascular smooth muscle cells in Alzheimer's disease brain, and has been demonstrated to mediate adhesion of microglia (another type of immune cell) to fibrillar amyloid- $\beta$. As concerns their own experiments, Thanopoulou et al. report that SRBI mediates perivascular macrophage response, and regulates amyloid- $\beta$ pathology and cerebral angiopathy in an Alzheimer's mouse model (i.e., human-amyloid precursor protein transgenic mouse). The authors remark that these findings designate SR-BI as a therapeutic 
target for treatment of Alzheimer's disease and cerebral amyloid angiopathy (Thanopoulou et al. 2010).

$>$ From all the foregoing findings in the preceding paragraph, it is evident that choosing an intravenous film-stabilized microbubble agent which targets cell-surface SR-BI could allow various above-described cell types, all potentially implicated in Alzheimer's disease, to be simultaneously searched out and likely reached for localized treatment (e.g., drug delivery). Due to the complexity of Alzheimer's disease, it is likely that therapeutics which target multiple cellular sites will result in a more efficient management of this disease, and might also be effective in various forms of Alzheimer's disease with different underlying pathophysiological mechanisms (Donev et al. 2009). As recently pointed out by Bredesen (2014), there is not any single drug currently available for Alzheimer's disease that exerts anything beyond a marginal, unsustained symptomatic effect, with little or no effect on disease progression. Bredesen further states that, in the past decade alone, hundreds of clinical trials have been conducted for treating Alzheimer's disease, at an aggregate cost of literally billions of dollars, without success. However, for both Alzheimer's disease as well as its predecessors, mild cognitive impairment and subjective cognitive impairment, comprehensive combination therapies (targeting multiple cellular sites) have not been explored. It is also possible that targeting multiple cellular sites, within the multiple-cell-type network underlying Alzheimer's disease pathophysiology, may be successful even when each [SR-BI bearing] cell type targeted is affected in a relatively modest way; that is to say, the effects on the various cell types targeted may be additive, multiplicative, or otherwise synergistic (Bredesen 2014).

\section{Past Targeted Nanotherapy using Lipid Nanoemulsions}

The above-stated desire for a multitasking combination therapeutic, capable of targeting (via SR-BI) the multiple-cell-type network underlying Alzheimer's disease pathophysiology, would be further fulfilled if the chosen intravenous microbubble agent could readily and demonstrably carry (one or more) useful small molecular drug(s). There is one multitasking therapeutic candidate, existing in the form of an intravenous film-stabilized microbubble agent which targets cell-surface SR-BI, that is documented to be a successful carrier of selected small molecular compound(s). Specifically, "lipid-coated microbubble (LCM) /nanoparticle-derived" lipid nanoemulsion, also known as LCM/ND lipid nanoemulsion type, is well-documented (D'Arrigo 2011) to be useful for highly selective delivery of (easily incorporated) lipophilic dyes, labels, or low-molecular-weight drugs to various types of solid tumors and certain other (noncancerous) hyperproliferative-disease lesions/sites. All these lesions consistently display an increased (cell-surface) expression and/or activity of lipoprotein receptors, including notably the (class B) scavenger receptor known as SR-BI (or sometimes as CLA-1 [the human SR-BI ortholog] ). Such data on SR-BI expression and function are noteworthy; namely, SR-BI has emerged as the lipoprotein receptor primarily involved in the enhanced endocytosis (i.e., enhanced intracellular uptake) of LCM/ND lipid nanoemulsions into hyperproliferative-disease sites (D'Arrigo 2011). First, as concerns tumors, an independent evaluation of this type of lipid nanoemulsion has appeared in a review 
article by Constantinides et al. (2008). At the same time, this particular study provides certain relevant data that is useful as a test of the expectation that a significantly enhanced endocytosis of LCM/ND lipid nanoemulsion (likely mediated by SR-BI) ought to be readily detectable in Hep3B human hepatoma cells. [This expectation arises from the fact that SRBI expression, which is well described for HepG2 cells, has also been documented in Hep3B cells. Furthermore, when studying the effect of chemical agents causing decreased SR-BI levels in Hep3B hepatoma cells, the same chemical agents were observed to cause decreased uptake of HDL lipids into Hep3B cells (for a review see D'Arrigo 2011).] In actuality, a noticeably enhanced uptake of this (dye-carrying) LCM/ND lipid nanoemulsion type into varied tumor cells is reported by Constantinides et al. (2008) and, as expected, the observed enhanced uptake is particularly marked in Hep3B hepatoma cells (see Table 24.1 in D'Arrigo 2011). The LCM/ND lipid nanoemulsion version employed by these authors is called Emulsiphan. Most solid tumors displayed enhanced uptake of this Emulsiphan version of (dye-labeled) LCM/ND lipid nanoemulsion; however, these tumors did not do so to the same degree. Nonetheless, it is noteworthy that all of the varied tumor cells listed in Table 24.1 (of D'Arrigo 2011) display a significantly increased uptake of this LCM/ND lipid nanoemulsion version (as compared to the undetectable level of Emulsiphan nanoemulsion uptake in parenteral 3T3-L1 cells which are noncancerous cells). (For added discussion, see Sect. 24.3 in D'Arrigo 2011.) Besides the above dye-labeling experiments, both Constantinides et al. (2008) and Ho et al. (1997) have formulated LCM/ND lipid nanoemulsions with the anticancer drug, paclitaxel, and documented the successful delivery (intracellularly) of the carried drug to tumor cells of various types (D'Arrigo 2011).

As concerns the above-mentioned "certain other (noncancerous) hyperproliferative-disease lesions/sites", which overexpress scavenger receptors, one example is central nervous system (CNS) injury -- that is brain injury and/or spinal cord injury. Various published studies indicate increased scavenger receptor expression on "proliferating macrophages" and "activated astrocytes" arising after CNS injury. At the same time, this increased scavenger receptor expression, which probably mainly involves SR-BI (see Sect. 25.1.1 in D'Arrigo 2011), provides a plausible avenue for targeted drug-delivery treatment of CNS-injury sites. Accordingly, Wakefield et al. (1998) examined the use of LCM/ND lipid nanoemulsion to deliver intravenuosly $7 ß$-hydroxycholesterol $(7 ß-\mathrm{OHC})$ to a radiofrequency (thermal) lesion in the rat brain. [7ß-OHC and other oxysterols have been reported, by other investigators, to inhibit astrogliosis both in vitro and in vivo (cf. D'Arrigo 2011).] Wakefield et al. (1998) observed that the number of activated astrocytes were reduced when treated with $73-\mathrm{OHC}$ delivered by the LCM/ND lipid nanoemulsion, while not affected by the same dose of intravenously injected $7 ß-\mathrm{OHC}$ in saline. It appears that the mechanism of this enhanced delivery of $7 ß-O H C$ to the brain-injury site, by a LCM/ND lipid nanoemulsion type, shares common features with the above tumor work. (For added discussion, see Chap. 13 and Sect. 24.3 in D'Arrigo 2011.) The above interpretation of the data receives additional indirect support from published findings, of other investigators, which document the expression of SR-BI on astrocytes and vascular smooth muscle cells in adult mouse and human brains -- as well as in Alzheimer's disease brain (D'Arrigo 2011). Lastly, this documented ability of LCM/ND lipid nanoemulsion to function as a carrier of selected small molecular compounds 
would, of course, be potentially applicable to certain drug molecules already being used in research for treating Alzheimer's disease (and brain injury). Several low-molecular-weight, and sufficiently lipophilic, candidates for incorporation into the LCM/ND lipid nanoemulsion are Edaravone (Jiao et al. 2015; Yang et al. 2015), caffeine (Chen et al. 2010; Chieffi et al. 2011; Marques et al. 2011; Mohan et al. 2015), resveratrol (Turner et al. 2015; Zhao et al. 2015), and docosahexaenoic acid or DHA (Cederholm et al. 2013; Hashimoto et al. 2016; Hjorth et al. 2013; Mayurasakorn et al. 2016; Pan et al. 2015; Vandal et al. 2014; Williams et al. 2013; Yassine et al. 2016a, 2016b).

\section{Serum Amyloid A (SAA), SR-BI, and Alzheimer's Disease}

The immune response after brain injury, and during neurodegenerative disorders, is highly complex -- involving both local and systemic events at the cellular and molecular level (Orsini et al. 2014). More specifically, inflammation of brain tissue in the absence of infection (sterile inflammation) contributes to acute brain injury and chronic disease. Accordingly, Savage et al. have studied the inflammatory responses of glial cells in the presence of a relevant endogenous priming stimulus; these authors report the acute-phaseprotein serum amyloid A (SAA) [see below] acted as a sterile, endogenous, priming stimulus on glial cells (Savage et al. 2012). Note that serum amyloid A (SAA) is a liver-derived "highdensity lipoprotein (HDL)"-associated apolipoprotein, whose level in the blood increases up to 1,000-fold in response to various injuries including trauma (e.g., CNS injury), inflammation (e.g., human vascular plaques and Alzheimer's lesions), etc. Like other acutephase reactants, the liver is the major site of SAA expression; however, SAA is also expressed in cells at inflammation sites, e.g., macrophage cell lines and within human atherosclerotic lesions (e.g., D'Arrigo 2011). Baranova et al. (2005) point out that the importance of SAA in various physiological and pathological processes has generated considerable interest in the identity of the cell-surface receptor(s) that bind, internalize, and mediate SAA-induced proinflammatory effects. Furthermore, these authors assert that the results of their study demonstrate that CLA-1 (the human SR-BI ortholog (Vishnyakova et al. 2003)) functions as an endocytic SAA receptor, and is involved in SAA-mediated cell signaling events associated with the immune-related and inflammatory effects of SAA (Baranova et al. 2005). In addition, CLA-1 and SR-BI are highly expressed on monocytes/macrophages, cells known to be the primary sites of SAA uptake (Baranova et al. 2005; Pearson 1996).

It is also worth noting that such blood-borne human monocytes (with their high expression of CLA-1/SR-BI and ability to differentiate into macrophages to elicit an immune response locally) have recently been reported (Darlington et al. 2015) to reduce Alzheimer's-like pathology and associated cognitive impairments in transgenic mice having Alzheimer's-like symptoms. Specifically, monocytes (derived from human umbilical cord blood cells) were found to play a central role in ameliorating cognitive deficits and reducing amyloid- $\beta$ neuropathology in an Alzheimer's mouse model (Darlington et al. 2015). This finding is consistent with an earlier study, by different investigators (Chang et al. 2009), which reported that very old SR-BI knockout mice show deficient synaptic plasticity (long-term potentiation) 
in the hippocampus. Also, very old SR-BI knockout mice were found to display impairments in recognition memory and spatial memory (Chang et al. 2009).

Returning to the above observations regarding SAA and inflammation, they are of added interest because inflammation is a known risk factor for Alzheimer's disease and the SAA concentration is much higher, in cerebrospinal fluid (CSF), in subjects with Alzheimer's disease than in controls (Miida et al. 2006). It was further found that SAA dissociated apolipoprotein E (apoE) from HDL, in the CSF, in a dose-dependent manner. Importantly, amyloid- $\beta$ fragments [i.e., 1-42] were bound to large CSF-HDL, but not to apoE dissociated by SAA. Miida et al. (2006) therefore postulate that inflammation in the CNS may impair amyloid- $\beta$ clearance due to loss of apoE from CSF-HDL. Moreover, it has recently been independently reported that SAA itself can misfold and potentially lead to systemic amyloidoses (Das and Gursky 2015).

\section{Treating Brain Injury, Neuroinflammation, and Alzheimer's Disease via LCM/ND Nanoemulsions}

The brief histological description of brain-injury sites, in the preceding four paragraphs, points to a larger pathophysiological overlap which exists between brain injury and Alzheimer's disease brain. First as concerns brain injury, Wang et al. (2011) have pointed out that non-neuronal brain cells, especially astrocytes (the predominant cell type in the human brain), may exert an active role in the pathogenesis of traumatic brain injury (TBI). Activated astrocytes may contribute to increased oxidative stress and neuroinflammation following neurotrauma. Interestingly, the drug Edaravone (also mentioned above [see 4 paragraphs back]) has been used successfully, in past research, for its neuroprotective and antioxidative effects on the brain after TBI. Wang et al. (2011) extended this research and found that, after intravenous administration (in rats), Edaravone treatment significantly decreased hippocampal neuron loss, reduced oxidative stress, and decreased neuronal programmed cell death as compared to control treatment. The protective effects of Edaravone treatment were also related to the pathology of TBI on non-neuronal cells, as Edaravone decreased both astrocyte and microglia activation following TBI. These authors conclude that the likely mechanism of Edaravone's neuroprotective effect, in the rat model of TBI, is via inhibiting oxidative stress leading to a decreased inflammatory response and decreased glial activation, and thereby reducing neuronal death and improving neurological function (Wang et al. 2011). Similarly, Itoh et al. (2010) have reported that Edaravone administration intravenously (in rats), following TBI, inhibited free radical-induced neuronal degeneration and apoptotic cell death around the damaged area. Hence, Edaravone treatment improved cerebral dysfunction following TBI, suggesting its potential as an effective clinical therapy (2010).

In view of the above description of TBI, the effects of the drug Edaravone, and the pathophysiological overlap of TBI with many characteristics of Alzheimer's disease brain (cf. above), it is logical and consistent that Jiao et al. (2015) have recently reported that Edaravone can also ameliorate Alzheimer's disease-type pathologies and cognitive deficits of a mouse model of Alzheimer's disease. Specifically, besides reducing amyloid- $\beta$ 
deposition and tau hyperphosphorylation, Edaravone was found to alleviate oxidative stress and, hence, attenuates the downstream pathologies including glial activation, neuroinflammation, neuronal loss, synaptic dysfunction, and rescues the memory deficits of the mice (Jiao et al. 2015). [Note that Edaravone is a small-molecule drug, which is known to function as a free-radical scavenger; it currently is being used clinically in Japan to treat (acute ischemic) stroke patients (Jiao et al. 2015; Wang et al. 2011).] Jiao et al. (2015) further state that their above findings suggest that Edaravone is a promising drug candidate for Alzheimer's disease by targeting multiple key pathways of the disease pathogenesis. This recommendation by Jiao et al. of Edaravone (for treating Alzheimer's disease) fits well with the initial drug candidates suggested, based on low-molecular-weight and sufficient lipophilicity, for incorporation into the LCM/ND lipid nanoemulsion proposed here (cf. above) to treat Alzheimer's disease. Since their recommendation is based in part on knowledge of failed clinical trials indicating that a single target or pathway does not work on this complex disease (Jiao et al. 2015), these investigators are understandably encouraged by a drug like Edaravone which targets multiple pathways of Alzheimer's disease pathogenesis.

Another drug candidate suggested above for incorporation into the LCM/ND nanoemulsion is docosahexaenoic acid, or DHA. It has recently been reported extensively, in numerous publications by various groups of investigators worldwide (e.g., Cederholm et al. 2013; Hashimoto et al. 2016; Hjorth et al. 2013; Mayurasakorn et al. 2016; Pan et al. 2015; Vandal et al. 2014; Williams et al. 2013; Yassine et al. 2016a, 2016b), that DHA has been used successfully to treat Alzheimer's symptoms in humans as well as animal models (and brain injury in animal models). [See also below.]

\section{Targeted Delivery (of drugs including antibody therapeutics) coordinated with Focused Sonoporation}

More generally, this overall nanotherapeutic approach to treating Alzheimer's disease, via $\operatorname{lipid}(\mathrm{LCM} / \mathrm{ND})$-nanoemulsion particles, is in harmony with the conclusions of a recent review on drug targeting to the brain (Mahringer et al. 2012). Of particular interest, Mahringer et al. (2012) point out that one noninvasive approach to overcome the blood-brain barrier (BBB) has been to increase lipophilicity [even further] of CNS drugs by use of colloidal drug-delivery carriers, e.g., surfactant/lipid-coated (polymeric) nanoparticles. These authors explain that, after intravenous injection, these surfactant-treated nanoparticles apparently bind to apolipoproteins (e.g., apoA-I in blood plasma) and are subsequently recognized by the corresponding lipoprotein receptors, namely, SR-BI type scavenger receptors at the BBB (Mahringer et al. 2012; cf. Sect. 25.2 in D'Arrigo 2011). In addition, Mahringer et al. (2012) further point out in their review that focused-ultrasound/microbubble (FUS/M) delivery of a model drug has been achieved in the past with minimal histological damage, while demonstrating markedly increased brain dosage (compared to background BBB "leak"), in transgenic Alzheimer's-disease mouse models (Raymond et al. 2008). Moreover, in another related study, the FUS/M strategy opened the BBB sufficiently to allow passage of compounds of at least $70 \mathrm{kDa}$ (but not greater than 2,000 kDa) into the brain parenchyma. This noninvasive and localized BBB-opening (i.e., sonoporation) technique 
could, therefore, provide an applicable mode to deliver nanoparticles of a range over several orders of magnitude of daltons (Choi et al. 2010; Mahringer et al. 2012; Timbie et al. 2015). As specifically concerns antibody therapeutics, a very recent review (Greene and Campbell 2016) cites a published example where dopamine receptor-targeted antibodies could cross the BBB following FUS/M delivery. Also, i.v. injection of anti-amyloid $\beta$ antibodies were observed to cross the BBB following FUS/M delivery and, furthermore, significantly reduced amyloid $\beta$ plaques (4-days) post treatment in a transgenic mouse model of Alzheimer's disease (Kinoshita et al. 2006; Sheikov et al. 2004).

Even without employing sonoporation, Mahringer et al. (2012) emphasize that brain uptake of large peptides like lipoproteins is mediated by endocytosis and/or transcytosis through peptide-specific receptors (e.g., scavenger receptors (SR)) which are now studied as target moieties for antibody-conjugated nanocarriers. Currently developed CNS drugs include large, hydrophilic molecules like antibodies; while approximately $100 \%$ of large molecules ordinarily do not cross the BBB, such large molecules (e.g., antibodies) do in fact pass the membrane barrier when delivered via receptor-mediated endocytosis. As Mahringer et al. (2012) point out in their detailed review, the BBB is equipped with several endocytotic receptors at the luminal surface (i.e., capillary endothelial membrane), including the type BI scavenger receptor (SR-BI). These reviewers state that coated nanoparticles represent one of the most innovative noninvasive approaches for drug delivery to the CNS; an important aspect for the commercial development of such nanoparticle systems is the fact that some of the materials employed have already been registered for parenteral use. The authors also cite work published in the past decade (consistent with separate Cav-Con, Inc.-collaborative studies published in the 1990s [see www.netplex.net/ cavcon]), using fluorescent-labeled coated nanoparticles and confocal laser scanning microscopy, which provide direct evidence that the [polymer-]coated nanoparticles crossed the BBB and distributed in the brain tissue after i.v. administration to rats (Mahringer et al. 2012).

Very recently, the same coated-microbubble approach has been successfully utilized by Mulik et al. (2016) for the targeted delivery of a particular therapeutic agent, namely DHA, into the brain. Specifically, lipoprotein nanoparticles reconstituted with docosahexaenoic acid (DHA) were employed due to the likelihood of their significant therapeutic value in the brain, since DHA is known to be neuroprotective (Mulik et al. 2016). Temporary, noninvasive BBB opening was achieved by Mulik et al. using pulsed ultrasound exposures in a localized brain region in normal rats, after which the (fluorescent-labeled or) DHA containing lipoprotein nanoparticles were administered intravenously. Fluorescent imaging of the rat brain tissue demonstrated that DHA was incorporated into the brain cells (and metabolized) in the ultrasound-exposed hemisphere. In addition, histological evaluation did not indicate any evidence of increased tissue damage in the ultrasound-exposed brain regions compared to normal brain. The authors concluded that their study demonstrates that localized delivery of DHA to the brain is possible using systemically-administered lipoprotein nanoparticles combined with pulsed focused ultrasound exposures in the brain (Mulik et al. 2016). (Other related nanoemulsion formulations for delivery of DHA have also been described recently (Walker et al. 2015).) 
Finally, (microbubble-assisted) sonoporation not only facilitates localized drug delivery (cf. above) but also the removal of amyloid- $\beta$ plaques from brain tissue in a mouse model (Leinenga and Gotz 2015). The mechanism of this plaque-burden reduction by sonoporation is believed to involve "loosening the tight junctions of the cells forming the BBB" (see Background); at the same time, it is worth noting that this same mechanism might also function to counteract characteristic decreased "brain clearance" of neurotoxic amyloid- $\beta$ "monomer" which has been described (Keaney et al. 2015) as a central event in the pathogenesis of Alzheimer's disease (cf. Alexopoulos et al. 2017). Namely, the recent biomolecular study by Keaney et al. (2015) reports that controlled modulation of tight junction components at the BBB can enhance the clearance (into the plasma) of soluble human amyloid- $\beta$ monomers from the brain in a murine model of Alzheimer's disease.

\section{Targeting Senile Endothelium, Brain Biometal (Fe, Ca) Dyshomeostasis, and Glucose- Transport/BBB Disruption}

By incorporating drug candidates (such as Edaravone, DHA, or antibody therapeutic) into the LCM/ND lipid nanoemulsion type, known to be a successful drug carrier (D'Arrigo 2011), one is likely to obtain a multitasking combination therapeutic for translational medicine. This therapeutic agent would target cell-surface SR-BI making possible for various (abovedescribed) cell types, all potentially implicated in Alzheimer's disease (cf. Krstic and Knuesel 2013; Wang 2014), to be simultaneously searched out and better reached for localized drug treatment of brain tissue in vivo. Further, it has been reconfirmed in the current literature that receptor-mediated endocytosis/transcytosis via lipoprotein receptors, particularly scavenger receptors including SR-BI, remains a major route for drug delivery across the blood-brain barrier; namely, recently published work has demonstrated that nanocomplexes can be readily transported into brain capillary endothelial cells [bovine and porcine] via SR-BI receptor-mediated endocytosis (Srimanee et al. 2016; -- see also Almer et al. 2015; Lajoie and Shusta 2015; Preston et al. 2014). Accordingly, endothelial modulation and repair become feasible by pharmacological targeting (Carradori et al. 2016; Di Marco et al. 2015; Hostenbach et al. 2016; Koizumi at al. 2016; Koster et al. 2016; Qosa et al. 2016; Salmina et al. 2010; Tong and Hamel 2015; Zenaro et al. 2016) via SR-BI receptors (cf. Hottman et al. 2014; Velagapudi et al. 2017). Since SR-BI has already been identified as a major receptor for LCM/ND nanoemulsions as well as HDL (with their major apolipoprotein [apo] A-I), the above therapeutic approach is quite consistent with the very recent finding that systemic (i.v.) administration of reconstituted (using human apo A-I) HDL can acutely modify brain amyloid- $\beta$ levels (in mice) which argues for further investigation of the therapeutic potential of apo A-I-based (SR-BI mediated) agents for Alzheimer's disease (Robert et al. 2016).

Moreover, the effects of the various cell types targeted (via SR-BI) may be additive, multiplicative, or otherwise synergistic. This therapeutic approach receives added impetus from continual findings of cerebrovascular pathology (Beishon et al. 2017; Goldwaser et al. 2016; Hishikawa et al. 2016; Kapasi and Schneider 2016; Kelleher and Soiza 2013; Malojcic et al. 2017; McAleese et al. 2016; Muche et al. 2017; Nelson et al. 2016; Nielsen et al. 2017; Noh et al. 2016; Perrotta et al. 2016; Raz et al. 2016; Weekman et al. 2016) and brain arterial 
aging (Calabrese et al. 2016; Cooper and Mitchell 2016; Gutierrez et al. 2016; Kelleher and Soiza 2013; Malojcic et al. 2017; Nagata et al. 2016; Raz et al. 2016; Toth et al. 2017) accompanying Alzheimer's disease. Similarly, there is an apparent endothelium-dysfunction involvement (Austin and Katusic 2016; Bhat 2015; Carradori et al. 2016; Chao et al. 2016; Devraj et al. 2016; Di Marco et al. 2015; Festoff et al. 2016; Gangoda et al. 2016; Hishikawa et al. 2016; Hostenbach et al. 2016; Kahlil et al. 2016; Kelleher and Soiza 2013; Koizumi at al. 2016; Koster et al. 2016; Muche et al. 2017; Qosa et al. 2016; Roberts et al. 2016; Salmina et al. 2010; Shang et al. 2016; Wang et al. 2017) in Alzheimer's disease as well as in its major risk factors (Austin et al. 2015; Austin and Katusic 2016; Bogush et al. 2017; Chao et al. 2016; Devraj et al. 2016; Festoff et al. 2016; Gangoda et al. 2016; Iadecola 2016; Kahlil et al. 2016; Kalaria et al. 2016; Kamat et al. 2016; Katusic and Austin 2016; Kelleher and Soiza 2013; Khan et al. 2016; Kyrtsos and Baras 2015; Perrotta et al. 2016; Roberts et al. 2016; Shang et al. 2016; Sheen and Sheu 2016; Toda and Okamura 2016; Toth et al. 2017;Uiterwijk et al. 2016; Vanhoutte et al. 2017; Wang et al. 2016). As early as three decades ago, the widely published neurohistologist/neuroclinician A.B. Scheibel (1987) described brain tissue specimens from clinically confirmed Alzheimer's patients showing much of the cerebral microvasculature totally lacking in the perivascular plexus of nerve fibers. He, and his coworkers, further suggested that widespread microvascular pathology may result from loss of the perivascular neural plexus (denervating microangiopathy), which could result in a failing blood-brain barrier and subsequent development of the disease (Scheibel 1987; Scheibel et al. 1989). Over these past decades, a frequent co-morbidity of cerebrovascular pathology and Alzheimer's disease pathology has been observed (Malojcic et al. 2017; Muche et al. 2017; Raz et al. 2016); as a result, there has been difficulty in clinically differentiating between Alzheimer's disease, vascular dementia, and mixed Alzheimer's disease/vascular dementia (Calabrese et al. 2016; McAleese et al. 2016; Raz et al. 2016; Tarantini et al. 2016). In fact, vascular dementia is considered the second most common cause of cognitive impairment after Alzheimer's disease in the elderly (Calabrese et al. 2016). On another level, there is also much evidence that endothelial dysfunction, due to cerebrovascular risk factors (that include diabetes, hypertension, and hypoxia) precedes cognitive decline in Alzheimer's disease and contributes to its pathogenesis (Austin and Katusic 2016; Iadecola 2016; Katusic and Austin 2016; Kelleher and Soiza 2013; Khalil et al. 2016; Wang et al. 2017). [ Note that "endothelial dysfunction", which in turn leads to general microvascular dysfunction, has recently been referred to as "a common pathway" pathophysiologically in obesity-associated diseases (Sorop et al. 2017). In particular, "brain microvascular endothelial cells" (BMECs), which are "known as the body's largest endocrine, paracrine and metabolic organ", generate and release many vasoactive substances (Zhu et al.2016); these include nitric oxide and endothelin-1, which maintain cerebrovascular homeostasis (Tan et al. 2015; Wang et al. 2014; Zhu et al. 2016).]

Accordingly, evidence has accumulated recently that diffusible mediators arising from vascular (endothelial) cells protect neurons from tau phosphorylation and, potentially, from progression of Alzheimer's disease pathology (Katusic and Austin 2016; Iadecola 2016). These findings suggest that preservation of healthy endothelium can be an important therapeutic target (Armstrong et al. 2015; Chakraborty et al. 2016; Dalkara and Alarcon- 
Martinez 2015; Gocmez et al. 2016; Giulia et al. 2016; Katusic and Austin 2016; Kelleher and Soiza 2013; Li et al. 2017; Pan et al. 2016; van de Haar et al. 2016; Velagapudi et al. 2017; Wu et al. 2016; Zhu et al. 2016). In this regard, another important function of the cerebrovascular endothelium is the transcellular trafficking of iron from the blood into the brain interstitium (Belaidi and Bush 2016; Beydoun et al. 2017; McCarthy and Kosman 2015a, 2015b; Pirpamer et al. 2016; Simpson et al. 2015). Brain iron homeostasis is increasingly reported (e.g., Belaidi and Bush 2016; Beydoun et al. 2017) as a potential target for the development of drug therapies for aging-related disorders (Belaidi and Bush 2016; Beydoun et al. 2017; McCarthy and Kosman 2015a; Pirpamer et al. 2016; Simpson et al. 2015). Dysregulation of iron metabolism, associated with cellular damage and oxidative stress, is reported as a common event in several neurodegenerative disorders including Alzheimer's disease (Belaidi and Bush 2016; Beydoun et al. 2017; McCarthy and Kosman 2015b; Simpson et al. 2015). More specifically, brain microvascular endothelial cells are believed to control iron uptake and efflux, under the direct guidance of neighboring astrocytes (Beydoun et al. 2017; McCarthy and Kosman 2015b). Detailed evidence has been reported recently (Beydoun et al. 2017) showing that human brain microvascular endothelial cells, which constitute most of the blood-brain barrier, receive brain-iron status information via paracrine signals from ensheathing astrocytes. Lastly, aging, obesity, and smoking are significant determinants of brain iron accumulation in human subjects (Pirpamer et al. 2016) and all have been long-associated with Alzheimer's disease incidence (Dalkara and AlarconMartinez 2015; Daulatzai 2016; Goldwaser et al. 2016; Nagata et al. 2016; Calabrese et al. 2016; Chao et al. 2016; Khalil et al. 2016; Khan et al. 2016; Tarantini et al. 2016; Toda and Okamura 2016; Toth et al. 2017).

In addition, recent work (Longden et al. 2016) has revealed that ion fluxes through diverse types of ion channels allow the cells of the neurovascular unit (i.e., comprising neurons, astrocytes, vascular smooth muscle cells, vascular endothelial cells, and pericytes) to engage in multicellular signaling processes that dictate local hemodynamics. For example, there are striking similarities in the ion channel complements employed in astrocytic endfeet and endothelial cells, enabling dual control of smooth muscle from either side of the blood-brain barrier (Longden et al. 2016; cf. Sudduth et al. 2017). Hence, the "neurovascular coupling" (NVC) signaling cascade recruits multiple cell types to link neural activity to a rise in local blood flow. If the NVC signaling cascade is impaired and cerebrovascular tone pathologically altered, local blood flow is compromised and neuronal dysfunction ensues. Cerebral blood flow is known to be disturbed both in neurodegenerative diseases (Alzheimer's disease and vascular dementia) and in a range of their risk factors (e.g., hypertension, stroke, and diabetes) (Arvanitakis et al. 2016; Bogush et al. 2017; Eskildsen et al. 2017; Kelleher and Soiza 2013; Longden et al. 2016; Love and Miners 2017; McInerney et al. 2017; Nielsen et al. 2017; Perrotta et al. 2016; Sheen and Sheu 2016; Sudduth et al. 2017). Moreover, brain imaging (via MRI) of human subjects $(n=143)$ yielded results showing brain iron deposits significantly associated with general cognitive ability in old age and with age-related cognitive decline (Penke et al. 2012). Also, in an earlier study of the clinical features of Alzheimer's disease (in 60 subjects), the most significant correlation observed was between blood Fe and Ca levels versus the severity of cognitive impairment (Bomboi 2005). In 
Alzheimer's disease, the abnormal interactions of $\beta$-amyloid peptide with metal ions such as iron are implicated in the process of $ß$-amyloid deposition and oxidative stress, resulting in disruption of cellular calcium homeostasis (Mattson 2004; Wan et al. 2011). (The proposed mechanism, suggested by various investigators in the past, involves the $ß$-amyloid/iron interaction leading to the formation of reactive oxygen species, followed by lipid peroxidation of the cell membrane(s), increased membrane fluidity, disturbance of calcium homeostasis, and finally cell death (e.g., Gerlach et al. 1994; Mattson 2004; see also Everett et al. 2014; Popugaeva et al. 2017; Tonnies and Trushina 2017).) Alternatively, other workers have recently emphasized (Kerr et al. 2017; Mamelak 2017; Wang et al. 2017) that the dysregulation of $\mathrm{Fe}$ and $\mathrm{Ca}$ levels, in Alzheimer's disease, originates within impaired mitochondria of cells in the neurovascular unit -- decades before cognitive deterioration (Mamelak 2017). Specifically, iron-induced oxidative damage (Wang et al. 2017) which results in impaired mitochondria leads to perturbed neuronal Ca levels, neuronal death, and eventually neurodegenerative disorders including Alzheimer's disease (Kerr et al. 2017; Mamelak 2017; Wang et al. 2017).

Note that the above-mentioned long association of specifically both obesity and diabetes with Alzheimer's disease incidence (cf. paragraph 3 and 4, respectively, in this Section) has also renewed attention to the brain's main facilitative glucose transporter protein, GLUT-1, involvement in and probable contribution to neurodegenerative diseases (Barros et al. 2017; Jais et al. 2016; Keaney and Campbell 2015). More than two decades ago it was already recognized that normal human-brain capillary endothelium has a high density of GLUT-1, whereas the cerebral microvessels in subjects with Alzheimer's disease showed a markedly decreased GLUT-1 density when compared with age-matched controls (Harik 1992; Horwood and Davies 1994). More recently, Winkler et al. (2015) demonstrated that GLUT1 deficiency in cerebral endothelium (but not in astrocytes), in a mouse model of Alzheimer's disease, initiates blood-brain barrier (BBB) breakdown. These authors observed from their detailed experiments that reduced GLUT-1 expression (at the BBB) worsens Alzheimer's disease cerebrovascular degeneration, neuropathology and cognitive function, suggesting that (cerebral endothelial) GLUT-1 may represent a therapeutic target for Alzheimer's disease vasculo-neuronal dysfunction and degeneration (Winkler et al. 2015).

More generally, the class of cellular regulators referred to as "protein chaperones" has suggested additional therapeutic targets for treating Alzheimer's-disease neurovascular dysfunction and degeneration (Everts 2017), -- especially since age is described as the foremost common risk factor for dementia (Cooper and Mitchell 2016). As emphasized in a very recent technical-news review (Everts 2017), advancing age of the host can affect protein homeostasis (or "proteostasis") which thereby becomes dysfunctional in a number of ways leading to a variety of diseases, including neurodegeneration, and aging. The above reviewer cites researchers who argue that many aging and age-related protein-aggregation diseases could be the result of chaperones losing their tight control on the complex array of effective, useful protein conformations in a cell. These and other researchers, cited in the technical review (Everts 2017), point out that mutations which produce problematically folded proteins might be overloading the proteostasis network -- especially later in life when human cells 
start producing fewer chaperones, which leads to dysregulation of proteostasis systems. Hence, various investigators have argued that molecules which kick-start or bolster the proteostasis network might represent good therapeutics for age-related protein-aggregation diseases and neurodegeneration (Everts 2017). Accordingly, recent experimental studies in rodent and human brain have indicated that loss of endothelial-cell homeostasis, which has been correlated experimentally (including via histochemical co-localization) with perturbation or compromise of the physiological role of certain cellular protein chaperones, may result in protein misfolding and creating aggregates as a key feature in neurodegenerative conditions such as Alzheimer's disease (E1 Hindy et al. 2014; Placido et al. 2017). In view of the above considerations, selected protein chaperones may reveal additional therapeutic targets for treating Alzheimer's-disease neurovascular dysfunction and degeneration.

In summary, endothelial cells are the main component of the blood-brain barrier (BBB), which is seriously disrupted in various neurological pathologies -- including many neurodegenerative disorders (Kelleher and Soiza 2013; Tenreiro et al. 2016; Yoon et al. 2017). Hence, vascular-targeted therapies become plausible for the prevention and treatment of common dementias (Beishon et al. 2017; Dichgans and Leys 2017; Kelleher and Soiza 2013; Love and Miners 2017; Velagapudi et al. 2017; Wang et al. 2017). In respect to vascular tone, vasodilators (nitric oxide, acetylcholine) are repressed while vasoconstrictor (endothelin-1) is enhanced, thus contributing to endothelial dysfunction in Alzheimer's disease (Lourenco et al. 2017; Tenreiro et al. 2016). Also, ß-amyloid can induce apoptosis and/or necrosis of brain endothelial cells. Presence of $\beta$-amyloid, as well as tau protein oligomers, leads to accumulation of inflammatory molecules in microvessels - which further fosters endothelial dysfunction (Castillo-Carranza et al. 2017; Dudvarski et al. 2016; Michalicova et al. 2017; Tenreiro et al. 2016). Other component cell types of the neurovascular unit are affected as well in Alzheimer's disease (Tenreiro et al. 2016). For example, deposition and aggregation of $ß$-amyloid within vascular smooth muscle cells leads to inflammation, oxidative stress, impaired vasorelaxation, and disruption of BBB integrity. At the same time, midlife vascular-risk factors such as hypertension, cardiovascular disease, diabetes, dyslipidemia, and obesity all increase the relative risk for Alzheimer's disease (Kelleher and Soiza 2013: Lee et al. 2017; Sorop et al. 2017; Stukas et al. 2014; Swaminathan et al. 2017). These co-morbidities are all characterized by low and/or dysfunctional HDL, which itself is an Alzheimer's risk factor. Namely, (in addition to long-published lipid transport,) HDL regulates vascular health via modulating vasorelaxation, inflammation, and oxidative stress as well as promoting endothelial cell survival and integrity (Guilaine et al. 2017; Stukas et al. 2014; Velagapudi et al. 2017).

In fact, very recently published experimental work (in human-endothelial-cell monolayer cultures as well as in three-dimensional tissue-engineered human vessels) has demonstrated in detail (Robert et al. 2017) that HDL, acts via scavenger receptors (class B type I, i.e., SR$\mathrm{BI}$ ), to block $\beta$-amyloid uptake into endothelial cells -- in experimental monolayers as well as, the authors argue, in the human cerebrovascular endothelium (Robert et al. 2017). [ These authors also point out that SR-BI is the principal HDL receptor on (human brain 
microvascular) endothelial cells and activates several HDL-signaling pathways (in addition to mediating selective cholesterol uptake) upon HDL docking. The authors observed that inhibiting SR-BI binding with a specific blocking antibody abolished the ability of HDL to suppress $\beta$-amyloid-induced monocyte adhesion to (human microvascular) endothelial cells. (Selectivity to SR-BI was confirmed by demonstrating that blocking scavenger receptor CD36 with a specific antibody had no effect on the ability of HDL to suppress $\beta$-amyloidmediated monocyte adhesion to endothelial cells) (Robert et al. 2017).] Also in 2017, Fung et al. separately report that SR-BI (Fung et al. 2017) mediates the uptake and transcytosis of HDL in brain microvascular endothelial cells (i.e., across the blood-brain barrier). These investigators further argue that manipulation of HDL transcytosis across the blood-brain barrier to increase delivery of apo A-I may, in turn, facilitate increasing transport of "HDLlike synthetic particles" containing therapeutic drug across the blood-brain barrier to treat neurodegenerative disorders such as Alzheimer's disease (Fung et al. 2017). Since SR-BI has already been identified as a major receptor for HDL (with their major apolipoprotein [apo] $A-I$ ) as well as for the earlier-described LCM/ND nanoemulsion, this multitasking lipid nanoemulsion can arguably serve as a targeted, apo A-I-based, (SR-BI mediated) therapeutic agent for Alzheimer's disease (Armstrong et al. 2015; Hottman et al. 2014; Robert et al. 2016, 2017; cf. Choi et al. 2016; Kitamura et al. 2017; Lazarus et al. 2015; Ma et al. 2015; Slot et al. 2017; Velagapudi et al. 2017; Yin et al. 2014).

\section{Implementation of Supplementary Neurotherapy using Targeted Sonoporation}

After introducing and summarizing various sonoporation studies in previous Sections, the clinical promise of sonoporation now warrants some details about its implementaion. Beyond the sizable clinical potential of targeted (receptor-mediated) drug delivery for treating common (Alzheimer's-related and/or vascular) dementias using the LCM/ND lipid nanoemulsion type, there exists the additional advantage of employing its characteristic lipidcoated microbubble (LCM) subpopulation (D'Arrigo 2011) for further targeted neurotherapy via sonoporation. This LCM subpopulation was utilized in the past for brain sonographic studies (D'Arrigo et al. 1991; D'Arrigo et al. 1993; Simon et al. 1990; Simon et al. 1992), neuro(CNS)-injury studies (Ho et al. 1997; Kureshi et al. 1999; Wakefield et al. 1998) and preliminary cavitation-therapy experiments (Simon et al. 1993) in animals -- all of which has been reviewed in detail elsewhere in the literature (D'Arrigo 2011).

Briefly, the LCM/ND lipid nanoemulsion class, which was modeled primarily from (nanoscale and mesoscale) self-assembling film-stabilized microbubbles in natural waters, is a low-cost stable (protein-free, non-phospholipid) biomolecular composition. This selfassembling lipid nanoemulsion contains specifically nonionic lipids exclusively (cf. D'Arrigo 1987, 1993) throughout the coated microbubble's and/or related nanoparticle's (i.e., related lipid polymorphs') supramolecular structure(s). The biobased lipid composition of LCM/ND nanoemulsions (i.e., glycerides and cholesterol compounds) is similar to lipids contained in several types of plasma lipoproteins; accordingly, when these LCM/ND nanoemulsion particles are injected into the bloodstream, they likely acquire (i.e., bind) plasma apolipoprotein(s) -- including notably apo A-I (D'Arrigo 2011). Hence, the molecular 
composition of the LCM/ND nanoemulsion particles resulted in both microbubble/nanoparticle stability and marked targeting toward tumors and certain other lesions; this very rapid targeting has been demonstrated to occur by an "active uptake" process, i.e., "endocytosis" -- which likely involves certain "lipoprotein receptor"-mediated endocytic pathways (D'Arrigo 2011).

The larger (LCM/ND-nanoemulsion) particles specifically represent the characteristic LCM subpopulation. These coated microbubbles (i.e., LCM) have been shown to also provide MRI contrast (Huang et al. 1993) due to their gas content. Namely, the rapid and selective accumulation of LCM in tumor tissue causes a significant change in the "bulk magnetic susceptibility" (BMS) inside tumors in vivo as detected by magnetic resonance imaging (MRI). This observed change in the BMS within the tumor tissue could only occur if the larger-diameter lipid-nanoemulsion particles did, in fact, represent "lipid-coated microbubbles" (LCM) which contained bulk (paramagnetic) gas, for example, air. In other words, the MRI nanoemulsion-contrast mechanism observed was that of a bulk-magneticsusceptibility increase from the local accumulation of the air-filled LCM inside the tumor mass, that is, from a significant increase of the local volume fraction of the gas microbubbles and therefore also the local BMS value (D'Arrigo 2011). Analogously, in past cavitationtherapy experiments using LCM, it was found that when a higher diagnostic-ultrasound output intensity is used, the larger (air-filled) nanoemulsion particles (i.e., LCM) vibrate more violently and burst (Simon et al. 1993).

This characteristic LCM subpopulation (within the LCM/ND-nanoemulsion total particle population) would now be available to substantially reduce the acoustic power levels needed for accomplishing endothelial sonoporation (cf. Skachkov et al. 2014), if additionally desired for further targeted neurotherapy of the Alzheimer's patient. Over the past decade, neuroscientists have been exploring the use of ultrasound and preformed microbubbles to temporarily open the blood-brain barrier (BBB) (Caskey et al. 2007; Choi et al. 2008, 2011; Konofagou 2012; McDannold et al. 2012; Raymond et al. 2007), allowing drugs or the immune system to target brain tumors or Alzheimer's brain plaque. It is believed (nonthermal focused) ultrasound pulses cause the (intravenously injected) preformed microbubbles to expand and contract (with acoustic pressure rarefaction and compression, respectively) against the BBB structure, thereby loosening the tight junctions (Leinenga and Gotz 2015; Torrice 2015) between endothelial cells which form the structural core of the BBB. Recently this research approach was employed by Leinenga and Gotz (2015) who utilized focused ultrasound coupled with intravenous injection of lipid-encased microbubbles. Their procedure design was sufficient to both remove amyloid- $\beta$ plaques in a mouse model of Alzheimer's disease, in which amyloid- $\beta$ is deposited in the brain, and to restore memory function in mice with Alzheimer's-like symptoms (Leinenga and Gotz 2015). More specifically, these investigators report that repeated scanning ultrasound (SUS) treatments, of the mouse brain, activated the invading microglia -- which in turn caused extensive internalization of amyloid- $\beta$ plaques into the lysosomes of activated microglia following the SUS treatments. Besides reducing plaque burden, the SUS-treated mice also displayed improved performance on three memory tasks (the Y-maze, the novel object recognition test, 
and the active place avoidance task). Leinenga and Gotz conclude that their findings suggest that repeated SUS is useful for removing amyloid- $\beta$ plaques in the mouse brain without causing observable damage, and should be explored further as a noninvasive method with potential as a (non-pharmacological) therapeutic approach for Alzheimer's disease (Leinenga and Gotz 2015).

The actual cellular and biophysical mechanism(s) of the reversible BBB "opening" process from sonoporation, when employing focused transcranial ultrasound coupled with injected preformed microbubbles, has been described further in other published studies over the last several years. For example, the preformed microbubbles concentrate the ultrasound effects to the microvasculature, greatly reducing the ultrasound exposure levels needed to produce bioeffects; thus, with injected microbubbles one can apply focused ultrasound transcranially without significant skull heating (Aryal et al. 2014; Xie et al. 2008). [ Note the term sonoporation has been used, in the literature, for describing both cell membrane and blood vessel permeabilization. Also, the repeated expansion and compression of microbubbles upon exposure to low acoustic pressures is referred to as stable or non-inertial cavitation (Dasgupta et al. 2016).] Because the circulating microbubbles appear to concentrate the ultrasound effects to the blood vessel walls, the temporary opening of the BBB occurs through widening of tight junctions between endothelial cells (and possibly also activation of transcellular mechanisms) with little effect on the surrounding brain parenchyma (Aryal et al. 2014; Dasgupta et al. 2016; Xie et al. 2008). This observed increase of BBB permeability is transient (i.e., the induced opening of the BBB is reversible) and apparently safe (Aryal et al. 2014; Xie et al. 2008), which is further supported by related cell-culture studies demonstrating viability of endothelial cells after ultrasound/microbubble-mediated sonoporation (Helfield et al. 2016; van Rooij et al. 2016). In particular, using human [umbilical vein] endothelial cell (HUVEC) monolayer cultures (Helfield et al. 2016), it was found that ultrasound/microbubble-mediated sonoporation results in observable acute cellular-pore generation (resealing time $<2 \mathrm{~min}$ ) and, more importantly, generates intercellular gaps between adjacent confluent HUVECs that persist over longer timescales ( 30-60 $\mathrm{min}$ ). Confocal-microscopy/cell-viability assays repeatedly confirmed that the cultured endothelial cells remained viable at 40-min post-ultrasound transmission, suggesting a visible mechanism for these authors' findings of prolonged, enhanced vascular permeability (Helfield et al. 2016) -- and again documenting that the ultrasound/microbubble-mediated opening of the BBB can be considered temporary, reversible, and apparently safe (Aryal et al. 2014; Dasgupta et al. 2016; Helfield et al. 2016; van Rooij et al. 2016; Xie et al. 2008).

Moreover, other investigators have recently pointed out (De Cock et al. 2015; Shapiro et al. 2016) that microbubble-mediated sonoporation is also believed to actually enhance local drug uptake across the cell membrane itself (e.g., of endothelial cells); namely, besides transient cellular-pore generation, the ultrasound-induced oscillation of local (preformed) microbubbles causes cell-membrane deformation -- which is hypothesized to induce or facilitate endocytosis (De Cock et al. 2015; Shapiro et al. 2016). More specifically, real-time confocal microscopy recording (during lower-acoustic-pressures ultrasound application) revealed that the membrane deformation by oscillating microbubbles may be the trigger for 
endocytosis via mechanostimulation of the cytoskeleton (De Cock et al. 2015). Hence, CNSendothelial sonoporation offers a range of neurotherapeutic options that can include either: 1) inducing/facilitating endocytosis (and, in turn, transcytosis); 2) transient cellular-pore generation; and/or 3) widening of tight junctions between endothelial cells of the cerebral microvasculature. These varied neurotherapeutic options are important and useful for both the researcher and the clinician -- because the BBB disruption associated with various neurological disorders (e.g., Alzheimer's disease, vascular dementia) has not been characterized in full detail cellularly. Namely, while the endothelial cells that form the structural core of the BBB normally have specialized tight junctions and extremely low rates of transcytosis (to limit flux of substances between the blood and CNS) (Andreone et al. 2017; Ben-Zvi et al. 2014; Chow and Gu 2017), the relative contributions of these altered properties to the disrupted BBB permeability in different neurodegenerative disorders (e.g., Alzheimer's disease) is unclear or unknown (Chow and $\mathrm{Gu} 2017$ ). In the foreseeable future, taking full advantage of this proposed minimally invasive and targeted use of preformed (LCM/ND nanoemulsion-based) microbubbles with sonoporation, while optimizing drug-delivery efficiency (through judicious choice of acoustic parameters) and minimizing side effects, may assist in advancing sonoporation to the clinic (cf. Aw et al. 2016; De Cock et al. 2015; Park et al. 2010; Shapiro et al. 2016).

\section{Conclusion}

The proposed multitasking combination therapeutic may also display greater effectiveness at different stages of Alzheimer's disease (cf. Wang 2014; Krstic and Knuesel 2013); as a result, this multitasking (drug-delivery) therapeutic could represent a promising way to treat, delay, or even prevent the disease in the future. Lastly, a completely separate and additional advantage of such LCM/ND lipid nanoemulsion(s), as a component of this combination therapeutic, stems from the characteristic lipid-coated microbubble subpopulation (D'Arrigo 2011) existing in this nanoemulsion type. Specifically, such preformed (lipid-stabilized) microbubbles are well known to substantially reduce the acoustic power levels needed for accomplishing temporary noninvasive (transcranial) ultrasound treatment (Adhikari et al. 2015; Alonso et al. 2010; Alonso et al. 2011; Aslund et al. 2017; Bing et al. 2014; D'Arrigo 2015; Delalande et al. 2013; Goliaei et al. 2015; Kotopoulis et al. 2013; Kotopoulis et al. 2014; Lammers et al. 2015; Marquet et al. 2011; Meairs 2015; Meng et al. 2017; Miller and O'Callaghan 2017), or sonoporation (Aubry et al. 2016;Bouakaz et al. 2016; Burgess and Hynynen 2016; Castle and Feinstein 2016; Delalande et al. 2015; Horodyckid et al. 2016; O'Reilly et al. 2017; Paefgen et al. 2015; Qin et al. 2016; Sennoga et al. 2016), if additionally desired for the Alzheimer's patient. 


\section{REFERENCES}

Adhikari U, Goliaei A, Berkowitz ML. Mechanism of membrane poration by shock wave induced nanobubble collapse: a molecular dynamics study. J Phys Chem B 2015;119:62256234.

Alexopoulos P, Gleixner LS, Werle L, Buhl F, Thierjung N, Giourou E, Kagerbauer SM, Gourzis P, Kubler H, Grimmer T, Yakushev I, Martin J, Kurz A, Perneczky R. Plasma levels of soluble amyloid precursor protein $\beta$ in symptomatic Alzheimer's disease. Eur Arch Psychiatry Clin Neurosci 2017; doi:10.1007/s00406-017-0815-9 .

Almer G, Mangge H, Zimmer A, Prassl R. Lipoprotein-related and apolipoprotein-mediated delivery systems for drug targeting and imaging. Curr Med Chem 2015;22:3631-3651.

Alonso A, Reinz E, Jenne JW, Fatar M, Schmidt-Glenewinkel H, Hennerici MG, Meairs S. Reorganization of gap junctions after focused ultrasound blood-brain barrier opening in the rat brain. J Cereb Blood Flow Metab 2010;30:1394-1402.

Alonso A, Reinz E, Fatar M, Hennerici MG, Meairs S. Clearance of albumin following ultrasound-induced blood-brain barrier opening is mediated by glial but not neuronal cells. Brain Res 2011;1411:9-16.

Andreone BJ, Chow BW, Tata A, Lacoste B, Ben-Zvi A, Bullock K, Deik AA, Ginty DD, Clish $\mathrm{CB}, \mathrm{Gu} \mathrm{C}$. Blood-brain barrier permeability is regulated by lipid transport-dependent suppression of caveolae-mediated transcytosis. Neuron 2017;doi:10.1016/j.neuron.2017.03.043 .

Armstrong SM, Sugiyama MG, Fung KYY, Gao Y, Wang C, Levy AS, Azizi P, Roufaiel M, Zhu SN, Neculai D, Yin C, Bolz SS, Seidah NG, Cybulsky MI, Heit B, Lee WL. A novel assay uncovers an unexpected role for SR-BI in LDL transcytosis. Cardiovasc Res 2015;108:268-277.

Arvanitakis Z, Capuano AW, Leurgans SE, Bennett DA, Schneider JA. Relation of cerebral vessel disease to Alzheimer's disease dementia and cognitive function in elderly people: a cross-sectional study. Lancet Neurol 2016;15:934-943.

Aryal M, Arvanitis CD, Alexander PM, McDannold N. Ultrasound-mediated blood-brain barrier disruption for targeted drug delivery in the central nervous system. Adv Drug Deliv Res 2014;72:94-109.

Aslund AKO, Snipstad S, Healey A, Kvale S, Torp SH, Sontum PC, de Lange Davies C, van Wamel A. Efficient enhancement of blood-brain barrier permeability using acoustic cluster therapy (ACT). Theranostics 2017;7:23-30. 
Aubry JF, Tanter M. MR-guided transcranial focused ultrasound. Adv Exp Med Biol 2016;880:97-111.

Austin SA, Santhanam AV, d'Uscio LV, Katusic ZS. Regional heterogeneity of cerebral microvessels and brain susceptibility to oxidative stress. PLoS One 2015;10:e0144062.

Austin SA, Katusic ZS. Loss of endothelial nitric oxide synthase promotes p25 generation and tau phosphorylation in a murine model of Alzheimer's disease. Circ Res 2016;119:11281134.

Aw MS, Paniwnyk L, Losic D. The progressive role of acoustic cavitation for non-invasive therapies, contrast imaging and blood-tumor permeability enhancement. Expert Opin Drug Deliv 2016;13:1383-1396.

Baranova IN, Vishnyakova TG, Bocharov AV, Kurlander R, Chen Z, Kimelman ML, Remaley AT, Csako G, Thomas F, Eggerman TL, Patterson AP. Serum amyloid A binding to CLA-1 (CD36 and LIMPII analogous-1) mediates serum amyloid A protein-induced activation of ERK1/2 and p38 mitogen-activated protein kinases. J Biol Chem $2005 ; 280: 8031-8040$.

Barros IF, San Martin A, Ruminot I, Sandoval PY, Fernandez-Moncada I, Baeza-Lehnert F, Arce-Molina R, Contreras-Baeza Y, Galaz A, Alegria K. Near-critical GLUT1 and neurodegeneration. J Neurosci Res 2017; doi:10.1002/jnr.23998 .

Beishon L, Haunton VJ, Panerai RB, Robinson TG. Cerebral hemodynamics in mild cognitive impairment: a systematic review. J Alzheimers Dis 2017; doi:10.3233/JAD-170181 .

Belaidi AA, Bush AI. Iron neurochemistry in Alzheimer's disease and Parkinson's disease: targets for therapeutics. J Neurochem 2016;139:179-197.

Ben-Zvi A, Lacoste B, Kur E, Andreone B, Mayshar Y, Yan H, Gu C. MFSD2A is critical for the formation and function of the blood-brain barrier. Nature 2014;509:507-511.

Beydoun R, Hamood MA, Gomez Zubeita M, Kondapalli KC. Na+/H+ exchanger 9 regulates iron mobilization at the blood-brain barrier in response to iron starvation. J Biol Chem 2017;doi:10.1074/jbc.M116.769240 .

Bhat NR. Vasculoprotection as a convergent, multi-targeted mechanism of anti-AD therapeutics and interventions. J Alzheimers Dis 2015;46:581-591.

Bing C, Ladouceur-Wodzak M, Wanner CR, Shelton JM, Richardson JA, Chopra R. Transcranial opening of the blood-brain barrier in targeted regions using a stereotaxic brain axis and focused ultrasound energy. J Ther Ultrasound 2014;2(\#13):1-11. 
Bogush M, Heldt NA, Persidsky Y. Blood brain barrier injury in diabetes: unrecognized effects on brain and cognition. J Neuroimmune Pharmacol 2017;doi:10.1007/s11481-0179752-7

Bomboi G, Marchione F, Sepe-Monti M, De Carolis A, Bianchi V, Medda E, Pino A, Bocca B, Forte G, D'Ippolito C, Giubilei F. Correlation between metal ions and clinical findings in subjects affected by Alzheimer's disease. Ann 1st Super Sanita 2005;41:205-212.

Bouakaz A, Zeghimi A, Doinikov AA. Sonoporation: concept and mechanisms. Adv Exp Med Biol 2016;880:175-189.

Bredesen DE. Reversal of cognitive decline: a novel therapeutic program. Aging (Albany, NY) 2014;6:707-717.

Burgess A, Hynynen K. Microbubble-assisted ultrasound for drug delivery in the brain and central nervous system. Adv Exp Med Biol 2016;880:293-308.

Calabrese V, Giordano J, Signorile A, Ontario ML, Castorina S, De Pasquale C, Eckert G, Calabrese EJ. Major pathogenic mechanisms in vascular dementia: roles of cellular stress response and hormesis in neuroprotection. J Neurosci Res 2016;94:1588-1603.

Carradori D, Gaudin A, Brambilla D, Andrieux K. Application of nanomedicine to the CNS diseases. Int Rev Neurobiol 2016;130:73-113.

Caskey CF, Stieger SM, Qin S, Dayton PA, Ferrara KW. Direct observations of ultrasound microbubble contrast agant interaction with the microvessel wall. J Acoust Soc Am 2007;122:1191-1200.

Castillo-Carranza DL, Nilson AN, Van Skike CE, Jahrling JB, Patel K, Garach P, Gerson JE, Sengupta U, Abisambra J, Nelson P, Troncoso J, Ungvari Z, Galvan V, Kayed R. Cerebral microvascular accumulation of tau oligomers in Alzheimer's disease and related tauopathies. Aging Dis 2017;8:257-266.

Castle J, Feinstein SB. Drug and gene delivery using sonoporation for cardiovascular disease. Adv Exp Med Biol 2016;880:331-338.

Cederholm T, Salem Jr N, Palmblad J. v-3 fatty acids in the prevention of cognitive decline in humans. Adv Nutr 2013;4:672-676.

Chakraborty A, de Wit NM, van der Flier WM, de Vries HE. The blood-brain barrier in Alzheimer's disease. Vascul Pharmacol 2017;89:12-18.

Chang EH, Rigotti A, Huerta P. Age-related influence of the HDL receptor SR-BI on synaptic plasticity and cognition. Neurobiol Aging 2009;30:407-419. 
Chao AC, Lee TC, Juo SH, Yang DI. Hyperglycemia increases the production of amyloid beta-peptide leading to decreased endothelial tight junction. CNS Neurosci Ther 2016;22:291-297.

Chen X, Ghribi O, Geiger JD. Caffeine protects against disruptions of the blood-brain barrier in animal models of Alzheimer's and Parkinson's disease. $\mathrm{J}$ Alzheimers Dis 2010;20(Suppl.1):S127-S141.

Chieffi S, La Marra M, Viggiano A, Messina G, De Luca V, Monda M. Caffeine protection against $\beta$-amyloid peptide toxicity in Alzheimer's disease. Curr Top Peptide Protein Res 2011;12:71-75.

Choi HJ, Seo EH, Yi D, Sohn BK, Choe YM, Byun MS, Lee JM, Woo JI, Lee DY. Amyloidindependent amnestic mild cognitive impairment and serum apolipoprotein A1 levels. Am J Geriatr Psychiatry 2016;24:144-153.

Choi JJ, Selert K, Vlachos F, Wong A, Konofagou EE. Noninvasive and localized neuronal delivery using short ultrasonic pulses and microbubbles. Proc Natl Acad Sci USA 2011;108:16539-16544.

Choi JJ, Wang S, Brown TR, Small SA, Duff KE, Konofagou EE. Noninvasive and transient blood-brain barrier opening in the hippocampus of Alzheimer's double transgenic mice using focused ultrasound. Ultrason. Imaging 2008;30:189-200.

Choi JJ, Wang S, Tung YS, Morrison 3rd B, Konofagou EE. Molecules of various pharmacologically-relevant sizes can cross the ultrasound-induced blood-brain barrier opening in vivo. Ultrasound Med Biol 2010;36:58-67.

Chow BW, Gu C. Gradual suppression of transcytosis governs functional blood-retinal barrier formation. Neuron 2017;93:1325-1333.

Constantinides PP, Chaubal MV, Shorr, R. Advances in lipid nanodispersions for parenteral drug delivery and targeting. Adv Drug Deliv Rev 2008;60:757-767.

Cooper LL, Mitchell GF. Aortic stiffness, cerebrovascular dysfunction, and memory. Pulse 2016;4:69-77.

Dalkara T, Alarcon-Martinez L. Cerebral microvascular pericytes and neurogliovascular signaling in health and disease. Brain Res. 2015;1623:3-17.

Darlington D, Li S, Hou H, Habib A, Tian J, Gao Y, Ehrhart J, Sanberg PR, Sawmiller D, Giunta B, Mori T, Tan J. Human umbilical cord blood-derived monocytes improve cognitive deficits and reduce amyloid- $\beta$ pathology in PSAPP mice. Cell Transplant 2015;24:2237-2250. 
D'Arrigo J. Surfactant mixtures, stable gas-in-liquid emulsions, and methods for the production of such emulsions from said mixtures. 1987;United States Patent No. 4,684,479 (issued 1987).

D'Arrigo J. Method for the production of medical-grade lipid-coated microbubbles, paramagnetic labeling of such microbubbles and therapeutic uses of microbubbles. 1993;United States Patent No. 5,215,680 (issued 1993).

D'Arrigo J. Stable nanoemulsions: Self-assembly in nature and nanomedicine. $415 \mathrm{pp}$. Amsterdam:Elsevier, 2011.

D'Arrigo JS. Nanotherapy for Alzheimer's. Chem Eng News 2015;93(\#41):2.

D'Arrigo JS, Ho SY, Simon RH. Detection of experimental rat liver tumors by contrastassisted ultrasonography. Invest Radiol 1993;28:218-222.

D'Arrigo JS, Simon RH, Ho SY. Lipid-coated uniform microbubbles for earlier sonographic detection of brain tumors. J. Neuroimag 1991;1:134-139.

Das M, Gursky O. Amyloid-forming properties of human apolipoproteins: sequence analyses and structural insights. Adv Exp Med Biol 2015;855:175-211.

Dasgupta A, Liu M, Ojha T, Storm G, Kiessling F, Lammers T. Ultrasound-mediated drug delivery to the brain: principles, progress and prospects. Drug Discov Today Technol 2016;20:41-48.

Daulatzai MA. Cerebral hypoperfusion and glucose hypometabolism: key pathophysiological modulators promote neurodegeneration, cognitive impairment, and Alzheimer's disease. J Neurosci Res 2017;95:943-972.

De Cock I, Zagato E, Braeckmans K, Luan Y, de Jong N, De Smedt SC, Lentacker I. Ultrasound and microbubble mediated drug delivery: acoustic pressure as determinant for uptake via membrane pores or endocytosis. J Control Rel 2015;197:20-28.

Delalande A, Kotopoulis S, Postema M, Midoux P, Pichon C. Sonoporation: mechanistic insights and ongoing challenges for gene transfer. Gene 2013;525:191-199.

Delalande A, Leduc C, Midoux P, Postema M, Pichon C. Efficient gene delivery by sonoporation is associated with microbubble entry into cells and the clathrin-dependent endocytosis pathway. Ultrasound Med Biol 2015;41:1913-1926.

Devraj K, Poznanovic S, Spahn C, Schwall G, Harter PN, Mittelbronn M, Antoniello K, Paganetti P, Muhs A, Heilemann M, Hawkins RA, Schrattenholz A, Liebner S. BACE-1 is expressed in the blood-brain barrier endothelium and is upregulated in a murine model of Alzheimer's disease. J Cereb Blood Flow Metab 2016;36:1281-1294. 
Dichgans M, Leys D. Vascular cognitive impairment. Circ Res 2017;120:573-591.

Di Marco LY, Venneri A, Farkas E, Evans PC, Marzo A, Frangi AF. Vascular dysfunction in the pathogenesis of Alzheimer's disease -- a review of endothelium-mediated mechanisms and ensuing vicious circles. Neurobiol Dis 2015;82:593-606.

Donev R, Kolev M, Millet B, Thome J. Neuronal death in Alzheimer's disease and therapeutic opportunities. J Cell Mol Med 2009;13:4329-4348.

Dudvarski Stankovic N, Teodorczyk M, Ploen R, Zipp F, Schmidt MH. Microglia-blood vessel interactions: a double-edged sword in brain pathologies. Acta Neuropathol 2016;131:347-363.

El Hindy M, Hezwani M, Corry D, et al. The branched-chain aminotransferase proteins: novel redox chaperones for protein disulfide isomerase - implications in Alzheimer's disease. Antioxid Redox Signal 2014;20:2497-2513.

Eskildsen SF, Gyldensted L, Nagenthiraja K, Nielsen RB, Bo Hansen M, Dalby RB, Frandsen J, Rodell A, Gyldensted C, Jespersen SN, Lund TE, Mouridsen K, Braendgaard H, Ostergaard L. Increased cortical capillary transit time heterogeneity in Alzheimer's disease: a DSC-MRI perfusion study. Neurobiol Aging 2017;50:107-118.

Everett J, Cespedes E, Shelford LR, Exley C, Collingwood JF, Dobson J, van der Laan G, Jenkins CA, Arenholz E, Telling ND. Ferrous iron formation following the co-aggregation of ferric iron and the Alzheimer's disease peptide $\beta$-amyloid (1-42). J R Soc Interface 2014; $11: 20140165$.

Everts S. Protein-folding mysteries. Chem Eng News 2017;95(\#31):32-38.

Festoff BW, Sajja RK, van Dreden P, Cucullo L. HGMB1 and thrombin mediate the bloodbrain barrier dysfunction acting as biomarkers of neuroinflammation and progression to neurodegeneration in Alzheimer's disease. J Neuroinflammation 2016;13:194.

Franco R, Cedazo-Minguez A. Successful therapies for Alzheimer's disease: why so many in animal models and none in humans? Front Pharmacol 2014;5(June):1-13.

Fung KYY, Wang C, Nyegaard S, et al. Scavenger receptor BI mediates the uptake and transcytosis of HDL in brain microvascular endothelial cells independent of PDZK1 and nitric oxide. FASEB J 2017;31(1):supplement 783.1 .

Gangoda SV, Butlin M, Gupta V, Chung R, Avolio A. Pulsatile stretch alters expression and processing of amyloid precursor protein in human cerebral endothelial cells. J Hypertens 2016;34:e24. 
Gerlach M, Ben-Shachar D, Riederer P, Youdim MB. Altered brain metabolism of iron as a cause of neurodegenerative diseases? J Neurochem 1994;63:793-807.

Giulia P, Michele L, Andrea F, Grazia D, Filomena C, Francesco P, Leandro C, Maria U, Carolina G, Massimiliano C, Antonio G. Brain atrophy, anti-smooth muscle antibody and cognitive impairment: an association study. Aging Dis 2015;7:318-325.

Gocmez SS, Scarpace PJ, Whidden MA, Erdos B, Kirichenko N, Sakarya Y, Utkan T, Turner $\mathrm{N}$. Age impaired endothelium-dependent vasodilation is improved by resveratrol in rat mesenteric arteries. J Exerc Nutrition Biochem 2016;20:41-48.

Goldwaser EL, Acharya NK, Sarkar A, Godsey G, Nagele RG. Breakdown of the cerebrovasculature and blood-brain barrier: a mechanistic link between diabetes mellitus and Alzheimer's disease. J Alzheimers Dis 2016;54:445-456.

Goliaei A, Adhikari U, Berkowitz ML. Opening of the blood-brain barrier tight junction due to shock wave induced bubble collapse: a molecular dynamics simulation study. ACS Chem Neurosci 2015;doi:10.1021/acschemneuro.5b00116 .

Greenberg SM (for MarkVCID consortium). Vascular disease and neurodegeneration: advancing together. Lancet Neurol 2017;16:333.

Greene C, Campbell M. Tight junction modulation of the blood-brain barrier: CNS delivery of small molecules. Tissue Barriers 2016;4:e1138017.

Guilaine B, Emily B, Sonja S, Cheryl W. The pleiotropic vasoprotective functions of high density lipoproteins (HDL). J Biomed Res 2017; doi:10.7555/JBR.31.20160133 .

Gutierrez J, Honig L, Elkind MS, Mohr JP, Goldman J, Dwork AJ, Morgello S, Marshall RS. Brain arterial aging and its relationship to Alzheimer dementia. Neurology 2016;86:15071515 .

Harik SI. Changes in the glucose transporter of brain capillaries. Can J Physiol Pharmacol 1992;70(Suppl.):S113-S117.

Hashimoto M, Hossain S, Al Mamun A, Matsuzaki K, Arai H. Docosahexaenoic acid: one molecule diverse functions. Crit Rev Biotechnol 2016; doi:10.1080/07388551.2016.1207153 .

Helfield B, Chen X, Watkins SC, Villanueva RS. Biophysical insight into mechanisms of sonoporation. Proc Natl Acad Sci 2016;113:9983-9988.

Hishikawa N, Fukui Y, Sato K, Kono S, Yamashita T, Ohta Y, Deguchi K, Abe K. Cognitive and affective functions in Alzheimer's disease patients with metabolic syndrome. Eur J Neurol 2016;23:339-345. 
Hjorth E, Zhu M, Toro VC, Vedin I, Palmblad J, Cederholm T, Freund-Levi Y, Faxen-Irving G, Wahlund LO, Basun H, Eriksdotter M, Schultzberg M. Omega-3 fatty acids enhance phagocytosis of Alzheimer's disease-related amyloid- 342 human microglia and decrease inflammatory markers. J Alzheimers Dis 2013;35:697-713.

Ho SY, Barbarese E, D'Arrigo JS, Smith C, Simon RH. Evaluation of lipid-coated microbubbles as a delivery vehicle for Taxol in tumor therapy. Neurosurgery 1997;40:12601268.

Ho SY, Li XG, Wakefield A, Barbarese E, D'Arrigo JS, Simon RH. The affinity of lipidcoated microbubbles for maturing brain injury sites. Brain Res Bull 1997;43:543-549.

Horodyckid C, Canney M, Vignot A, Boisgard R, Drier A, Huberfeld G, Francois C, Prigent A, Santin MD, Adam C, Willer JC, Lafon C, Chapelon JY, Carpentier A. Safe long-term repeated disruption of the blood-brain barrier using an implantable ultrasound device: a multiparametric study in a primate model. J Neurosurg 2016;10:1-11.

Horwood N, Davies DC. Immunolabelling of hippocampal microvessel glucose transporter protein is reduced in Alzheimer's disease. Virchows Arch 1994;425:69-72.

Hostenbach S, D'haeseleer M, Kooijman R, De Keyser J. The pathophysiological role of astrocytic endothelin-1. Prog Neurobiol 2016;144:88-102.

Hottman DA, Chernick D, Cheng S, Wang Z, Li L. HDL and cognition in neurodegenerative disorders. Neurobiol Dis 2014;72:22-36.

Huang W, Grecula JC, Button TM, Harrington DP, Davis MA, D'Arrigo JS, Laster BH, Springer CS. Use of lipid-coated microbubbles (LCMs) for susceptibility-based MRI contrast in brain tumors. In: Proceedings of the 12th Annual Meeting of the Society of Magnetic Resonance in Medicine. New York, 1993.

Iadecola C. Untangling neurons with endothelial nitric oxide. Circ Res 2016;119:1052-1054.

Itoh T, Satou T, Nishida S, Tsubaki M, Imano M, Hashimoto S, Ito H. Edaravone protects against apoptotic neuronal cell death and improves cerebral function after traumatic brain injury in rats. Neurochem Res 2010;35:348-355.

Jais A, Solas M, Backes H, Chaurasia B, Kleinridders A, Theurich S, Mauer J, Steculorum SM, Hampel B, Goldau J, Alber J, Forster CY, Eming SA, Schwaninger M, Ferrara N, Karsenty G. Myeloid-cell-derived VEGF maintains brain glucose uptake and limits cognitive impairmentin obesity. Cell 2016;165:882-895.

Jiao SS, Yao XQ, Liu YH, Wang QH, Zeng F, Lu JJ, Liu J, Zhu C, Shen LL, Liu CH, Wang YR, Zeng GH, Parikh A, Chen J, Liang CR, Xiang Y, Bu XL, Deng J, Li J, Xu J, Zeng YQ, $\mathrm{Xu}$ X, H. Xu W, Zhong JH, Zhou HD, Zhou XF, Wang YJ. Edaravone alleviates Alzheimer's 
disease-type pathologies and cognitive deficits. Proc Natl Acad Sci USA 2015;112:52255230 .

Kahlil A, Berrougui H, Pawelec G, Fulop T. Impairment of the ABCA1 and SR-BI-mediated cholesterol efflux pathways and HDL anti-inflammatory activity in Alzheimer's disease. Mech Ageing Dev 2012;133:20-29.

Kalaria RN. Neuropathological diagnosis of vascular cognitive impairment and vascular dementia with implications for Alzheimer's disease. Acta Neuropath 2016;131:659-685.

Kalaria RN, Akinyemi R, Ihara M. Stroke injury, cognitive impairment and vascular dementia. Biochim Biophys Acta 2016;1862:915-925.

Kamat PK, Kyles P, Kalani A, Tyagi N. Hydrogen sulfide ameliorates homocysteine-induced Alzheimer's disease-like pathology, blood-brain barrier disruption, and synaptic disorder. Mol Neurobiol 2016;53:2451-2467.

Kapasi A, Schneider JA. Vascular contributions to cognitive impairment, clinical Alzheimer's disease, and dementia in older persons. Biochim Biophys Acta 2016;1862:878886.

Katusic ZS, Austin SA. Neurovascular protective function of endothelial nitric oxide: recent advances. Circ J 2016;80:1499-1503.

Keaney J, Campbell M. The dynamic blood-brain barrier. FEBS J 2015;282:4067-4079.

Keaney J, Walsh DM, O'Malley T, Hudson N, Crosbie DE, Loftus T, Sheehan F, McDaid J, Humphries MM, Callanan JJ, Brett FM, Farrell MA, Humphries P, Campbell M. Autoregulated paracellular clearance of amyloid- $\beta$ across the blood-brain barrier. Sci Adv 2015;1:e1500472.

Kelleher RJ, Soiza RL. Evidence of endothelial dysfunction in the development of Alzheimer's disease: is Alzheimer's a vascular disorder? Am J Cardiovasc Dis 2013;3:197226.

Kerr JS, Adriaanse BA, Greig NH, Mattson MP, Cader MZ, Bohr VA, Fang EF.. Mitophagy and Alzheimer's disease: cellular and molecular mechanisms. Trends Neurosci 2017; doi:10.1016/j.tins.2017.01.002 .

Khalil RB, Khoury E, Koussa S. Linking multiple pathogenic pathways in Alzheimer's disease. World J Psychiatry 2016;6:208-214.

Khan A, Kalaria RN, Corbett A, Ballard C. Update on vascular dementia. J Geriatr Psychiatry Neurol 2016;29:281-301. 
Kinoshita M, McDannold N, Jolesz FA, Hynynen K. Targeted delivery of antibodies through the blood-brain barrier by MRI-guided focused ultrasound. Biochem Biophys Res Commun 2006;340:1085-1090.

Kitamura Y, Usami R, Ichihara S, Kida H, Satoh M, Tomimoto H, Murata M, Oikawa S. Plasma protein profiling for potential biomarkers in the early diagnosis of Alzheimer's disease. Neurol Res 2017;39:231-238.

Koizumi K, Wang G, Park L. Endothelial dysfunction and amyloid- $\beta$-induced neurovascular alterations. Cell Mol Neurobiol 2016;36:155-165.

Konofagou EE. Optimization of the ultrasound-induced blood-brain barrier opening. Theranostics 2012;2:1223-1237.

Koster KP, Thomas R, Morris AW, Tai LM. Epidermal growth factor prevents oligomeric amyloid- $\beta$ induced angiogenesis deficits in vitro. J. Cereb. Blood Flow Metab. 2016;36:18651871.

Kotopoulis S, Dimcevski G, Gilja OH, Hoem D, Postema M. Treatment of human pancreatic cancer using combined ultrasound, microbubbles, and gemcitabine: a clinical case study. Med Phys 2013;40:072902.

Kotopoulis S, Delalande A, Popa M, Mamaeva V, Dimcevski G, Gilja OH, Postema M, B. T. Gjertsen BT, McCormack E. Sonoporation-enhanced chemotherapy significantly reduces primary tumour burden in an orthotopic pancreatic cancer xenograft. Mol Imaging Biol 2014;16:53-62.

Krstic D, Knuesel I. Deciphering the mechanism underlying late-onset Alzheimer's disease. Nat Rev Neurol 2013;9:25-34.

Kureshi IU, Ho SY, Onyiuke HC, Wakefield AE, Kureshi IkU, D'Arrigo JS, Simon RH. The affinity of lipid-coated microbubbles to maturing spinal cord injury sites. Neurosurgery 1999;44:1047-1053.

Kyrtsos CR, Baras JS. Modeling the role of the glymphatic pathway and cerebral blood vessel properties in Alzheimer's disease pathogenesis. PLoS One 2015;10:e139574.

Lajoie JM, Shusta EV. Targeting receptor-mediated transport for delivery of biologics across the blood-brain barrier. Annu Rev Pharmacol Toxicol 2015;55:613-631.

Lammers T, Koczera P, Fokong S, Gremse F, Ehling J, Vogt M, Pich A, Storm G, van Zandvoort M, Kiessling F. Theranostic USPIO-loaded microbubbles for mediating and monitoring blood-brain barrier permeation. Adv Funct Mater 2015;25:36-43. 
Lazarus J, Mather KA, Armstrong NJ, Song F, Poljak A, Thalamuthu A, Lee T, Kochan NA, Brodaty H, Wright MJ, Ames D, Sachdev PS, Kwok JB. DNA methylation in the apolipoprotein-A1 gene is associated with episodic memory performance on healthy older individuals. J Alzheimers Dis 2015;44:175-182.

Lee LL, Aung HH, Wilson DW, Anderson SE, Rutledge JC, Rutkowsky JM. Triglyceriderich lipoprotein lipolysis products increase blood-brain barrier transfer coefficient and induce astrocyte lipid droplets and cell stress. Am J Physiol Cell Physiol 2017;312:C500-C516.

Leinenga G, Gotz J. Scanning ultrasound removes amyloid- $\beta$ and restores memory in an Alzheimer's disease mouse model. Sci Transl Med 2015;7:278ra33.

Li X, Lu F, Li W, Qin L, Ge X, Yu Q, Liang X, Zhao D, Li X, Zhang J. Edaravone injection reverses learning and memory deficits in a rat model of vascular dementia. Acta Biochim Biophys Sin (Shanghai) 2017;49:83-89.

Longden TA, Hill-Eubanks DC, Nelson MT. Ion channel networks in the control of cerebral blood flow. J Cereb Blood Flow Metab 2016;36:492-512.

Lourenco CF, Ledo A, Barbosa RM, Laranjinha J. Neurovascular uncoupling in the triple transgenic model of Alzheimer's disease: impaired cerebral blood flow response to neuronalderived nitric oxide signaling. Exp Neurol 2017;291:36-43.

Love S, Miners JS. Small vessel disease, neurovascular regulation and cognitive impairment: post-mortem studies reveal a complex relationship, still poorly understood. Clin Sci (Lond) 2017;131:1579-1589.

Ma C, Li J, Bao Z, Ruan Q, Yu Z. Serum levels of apo A1 and apo A2 are associated with cognitive status in older men. Biomed Res Int 2015;2015:481621.

Mahringer A, Reichel V, Ott M, MacLean C, Reimold I, Hollnack-Pusch E, Fricker G. Overcoming the blood brain barrier: the challenge of brain drug targeting. J Nanoneurosci 2012;2:5-19.

Malojcic B, Giannakopoulos P, Sorond FA, Azevedo E, Diomedi M, Oblak JP, Carraro N, Boban M, Olah L, Schreiber SJ, Pavlovic A, Garami Z, Bornstein NM, Rosengarten B. Ultrasound and dynamic functional imaging in vascular cognitive impairment and Alzheimer's disease. BMC Med 2017;15:27.

Mamelak M. Energy and the Alzheimer brain. Neurosci Biobehav Rev 2017;75:297-313.

Manukhina EB, Downey HF, Shi X, Mallet RT. Intermittent hypoxia training protects cerebrovascular function in Alzheimer's disease. Exp Biol Med 2016;241:1351-1363. 
Marques S, Batalha VL, Lopez LV, Outeiro TF. Modulating Alzheimer's disease through caffeine: a putative link to epigenetics. J Alzheimer's Dis 2011;24:161-171.

Marquet F, Tung YS, Teichert T, Ferrera VP, Konofagou EE. Noninvasive, transient and selective blood-brain barrier opening in non-human primates in vivo. PloS ONE 2011;6:e22598.

Mattson MP. Metal-catalyzed disruption of membrane protein and lipid signaling in the pathogenesis of neurodegenerative disorders. Ann N Y Acad Sci 2004;1012:37-50.

Mayurasakorn K, Niatsetskaya ZV, Sosunov SA, Williams JJ, Zirpoli H, Vlasakov I, Deckelbaum RJ, Ten VS. DHA but not EPA emulsions preserve neurological and mitochondrial function after brain hypoxia-ischemia in neonatal mice. PLoS One 2016;11:e0160870.

McAleese KL, Alafuzoff I, Charidimou A, De Reuck J, Grinberg LT, Hainsworth AH, Hortobagyi T, Ince P, Jellinger K, Gao J, Kalaria RN, Kovacs GG, Kovari E, Love S, Popovic M, Skrobot O, Taipa R, Thal DR, Werring D, Wharton SB, Attems J. Post-mortem assessment in vascular dementia: advances and aspirations. BMC Medicine 2016;14:129.

McCarthy RC, Kosman DJ. Mechanisms and regulation of iron trafficking across the capillary endothelial cells of the blood-brain barrier. Front Mol Neurosci 2015a;8:31.

McCarthy RC, Kosman DJ. Iron transport across the blood-brain barrier: development, neurovascular regulation and cerebral amyloid angiopathy. Cell Mol Life Sci 2015b;72:709727.

McDannold N, Arvanitis CD, Vykhodtseva N, Livingstone MS. Temporary disruption of the blood-brain barrier by use of ultrasound and microbubbles: safety and efficacy eveluation in rhesus macaques. Cancer Res 2012;72:3652-3663.

McInerney M, Short JL, Nicolazzo JA. Neurovascular alterations in Alzheimer's disease: transporter expression profiles and CNS drug access. AAPS J 2017; doi:10.1208/s12248-0170077-5.

Meairs S. Facilitation of drug transport across the blood-brain barrier with ultrasound and microbubbles. Pharmaceutics 2015;7:275-293.

Meng Y, Volpini M, Black S, Lozano AM, Hynynen K, Lipsman N. Focused US as a novel strategy for Alzheimer's disease therapeutics. Ann Neurol 2017;doi:10.1002/ana.24933 .

Michalicova A, Banks WA, Legath J, Kovac SA. Tauopathies - focus on changes at the neurovascular unit. Curr Alzheimer Res 2017; doi:10.2174/1567205014666170203143336 . 
Miida T, Yamada T, Seino U, Ito M, Fueki Y, Takahashi A, Kosuge K, Soda S, Hanyu O, Obayashi K, Miyazaki O, Okada M. Serum amyloid A (SAA)-induced remodeling of CSFHDL. Biochim Biophys Acta 2006;1761:424-433.

Miller DB, O'Callaghan JP. New horizons for focused ultrasound (FUS) - therapeutic applications in neurodegenerative diseases. Metabolism 2017;69S:S3-S7.

Mohan A, Roberto AJ, Mohan A, Liogier-Weyback L, Guha R, Ravishankar N, Rebello C, Kumar A, Mohan R. Caffeine as treatment for Alzheimer's disease: a review. J Caffeine Res 2015; doi:10.1089/jcr.2014.0027.

Muche A, Arendt T, Schliebs R. Oxidative stress affects processing of amyloid precursor protein in vascular endothelial cells. PLoS One 2017;12:e0178127.

Mulik RS, Bing C, Ladouceur-Wodzak M, Munaweera I, Chopra R, Corbin IR. Localized delivery of low-density lipoprotein docosahexaenoic acid nanoparticles to the rat brain using focused ultrasound. Biomaterials 2016;83:257-268.

Nagata K, Yamazaki T, Takano D, Maeda T, Fujimaki Y, Nakase T, Sato Y. Cerebral circulation in aging. Ageing Res Rev 2016;30:49-60.

Nelson AR, Sweeney MD, Sagare AP, Zlokovic BV. Neurovascular dysfunction and neurodegeneration in dementia and Alzheimer's disease. Biochim Biophys Acta 2016;1862:887-900.

Nielsen RB, Egefjord L, Angleys H, Mouridsen K, Gej1 M, Moller A, Brock B, Braendgaard H, Gottrup H, Rungby J, Eskildsen SF, Ostergaard L. Capillary dysfunction is associated with symptom severity and neurodegeneration in Alzheimer's disease. Alzheimers Dement 2017;doi:10.1016/j.jalz.2017.02.007 .

Noh Y, Seo SW, Jeon S, Lee JM, Kim JS, Lee JH, Kim JH, Kim GH, Ye BS, Cho H, Kim HJ, Yoon CW, Choe YS, Lee KH, Weiner MW, Na DL. The role of cerebrovascular disease in amyloid deposition. J Alzheimers Dis 2016;54:1015-1026.

O'Reilly MA, Hough O, Hynynen K. Blood-brain barrier closure time after controlled ultrasound-induced opening is independent of opening volume. J Ultrasound Med 2017;36:475-483.

Orsini F, D. De Blasio, Zangari R, Zanier ER, De Simoni MG. Versatility of the complement system in neuroinflammation, neurodegeneration and brain homeostasis. Front Cell Neurosci 2014; doi:10.3389/fncel.2014.00380 .

Paefgen V., Doleschel D, Kiessling F. Evolution of contrast agents for ultrasound imaging and ultrasound-mediated drug delivery. Front Pharm 2015;6.197. 
Pan Y, Khalil H, Nicolazzo JA. The impact of docosahexaenoic acid on Alzheimer's disease: is there a role of the blood-brain barrier? Curr Clin Pharmacol 2015;10:222-241.

Pan Y, Short JL, Choy KH, Zeng AX, Marriott PJ, Owada Y, Scanlon MJ, Porter CJ, Nicolazzo JA. Fatty acid-binding protein 5 at the blood-brain barrier regulates endogenous brain docosahexaenoic acid levels and cognitive function. J Neurosci 2016,36:11755-11767 .

Park J, Fan Z, Kumon RE, El-Sayed ME, Deng CX. Modulation of intracellular Ca2+ concentration in brain microvascular endothelial cells in vitro by acoustic cavitation. Ultrasound Med Biol 2010;36:1176-1187.

Pearson A. Scavenger receptors in innate immunity. Curr Opin Immunol 1996;8:20-28.

Penke L, Valdes Hernandez MC, Maniega SM, Gow AJ, Murray C, Starr JM, Bastin ME, Deary IJ, Wardlaw JM. Brain iron deposits are associated with general cognitive ability and cognitive aging. Neurobiol Aging 2012;33:510-517.

Perrotta M, Lembo G, Carnevale D. Hypertension and dementia: epidemiological and experimental evidence revealing a detrimental relationship. Int J Mol Sci 2016;17:347.

Pirpamer L, Hofer E, Gesierich B, De Guio F, Freudenberger P, Seiler S, Duering M, Jouvent E, Duchesnay E, Dichgans M, Ropele S, Schmidt R. Determinants of iron accumulation in the normal aging brain. Neurobiol Aging 2016;43:149-155.

Placido AI, Pereira CM, Correira SC, et al. Phosphatase 2A inhibition affects endoplasmic reticulum and mitochondria homeostasis via cytoskeletal alterations in brain endothelial cells. Mol Neurobiol 2017;54:154-168.

Popugaeva E, Pchitskaya E, Bezprozvanny I. Dysregulation of neuronal calcium homeostasis in Alzheimer's disease: a therapeutic opportunity? Biochem Biophys Res Comm 2017;483:998-1004.

Preston JE, Abbott J, Begley DJ. Transcytosis of macromolecules at the blood-brain barrier. Adv Pharmacol 2014;71:147-163.

Qin J, Wang TY, Willmann JK. Sonoporation: applications for cancer therapy. Adv Exp Med Biol (Therapeutic Ultrasound) 2016;880:263-291.

Qosa H, Mohamed A, Al Rihani SB, Batarseha YS, Duong QV, Keller JN, Kaddoumi A. High-throughput screening for identification of blood-brain barrier integrity enhancers: a drug repurposing opportunity to rectify vascular amyloid toxicity. J Alzheimers Dis 2016;53:1499-1516.

Raymond SB, Skoch J, Hynynen K, Bacskai BJ. Multiphoton imaging of ultrasound/Optison mediated cerebrovascular effects in vivo. J Cereb Blood Flow Metab 2007;27:393-403. 
Raymond SB, Treat LH, Dewey JD, McDannold NJ, Hynynen K, B. J. Bacska BJ. Ultrasound enhanced delivery of molecular imaging and therapeutic agents in Alzheimer's disease mouse models. PLoS One 2008;3:e2175.

Raz L, Knoefel J, Bhaskar K. The neuropathology and cerebrovascular mechanisms of dementia. J Cereb Blood Flow Metab 2016;36:172-186.

Robert J, Stukas S, Button E, Cheng WH, Lee M, Fan J, Wilkinson A, Kulic I, Wright SD, Wellington CL. Reconstituted high-density lipoproteins acutely reduce soluble brain Aß levels in symptomatic APP/PS1 mice. Biochim Biophys Acta 2016;1862:1027-1036.

Robert J, Button EB, Stukas S, et al. High-density lipoproteins suppress A $\beta$-induced PBMC adhesion to human endothelial cells in bioengineered vessels and in monoculture. Mol Neurodegener 2017;12:60.

Roberts AM, Jagadapillai R, Vaishnav RA, Friedland, Drinovac R, Lin X, Gozal E. Increased pulmonary arteriolar tone associated with lung oxidative stress and nitric oxide in a mouse model of Alzheimer's disease. Physiol Rep 2016;4:e12953.

Salmina AB, Inzhutova AI, Malinovskaya NA, Petrova MM. Endothelial dysfunction and repair in Alzheimer-type neurodegeneration: neuronal and glial control. J Alzheimers Dis 2010;22:17-36.

Savage CD, Lopez-Castejon G, Denes A, Brough D. NLRP3-inflammasome activating DAMPs stimulate an inflammatory response in glia in the absence of priming which contributes to brain inflammation after injury. Front Immunol 2012;3:288.

Scheibel AB. Alterations of the cerebral capillary bed in the senile dementia of Alzheimer. Ital J Neurol Sci 1987;8:457-463.

Scheibel AB, Duong TH, Jacobs R. Alzheimer's disease as a capillary dementia. Ann Med 1989;21:103-107.

Sennoga CA, Kanbar E, Auboire L, Dujardin PA, Fouan D, Escoffre JM, Bouakaz A. Microbubble-mediated ultrasound drug-delivery and therapeutic monitoring. Expert Opin Drug Deliv 2016;11:1-13.

Shang S, Yang YM, Zhang H, Tian L, Jiang JS, Dong YB, Zhang K, Li B, Zhao WD, Fang WG, Chen YH. Intracerebral GM-CSF contributes to transendothelial monocyte migration in APP/PS1 Alzheimer's disease mice. J Cereb Blood Flow Metab 2016;36:1978-1991.

Shapiro G, Wong A, Bez M, Yang F, Tam S, Even L, Sheyn D, Ben-David S, Tawackoli W, Pelled G, Ferrara KW, Gazit D. Multiparameter evaluation of in vivo gene delivery using ultrasound-guided, microbubble-enhanced sonoporation. J Control Rel 2016;223:157-164. 
Sheen YJ, Sheu WH. Association between hypoglycemia and dementia in patients with type 2 diabetes. Diabetes Res Clin Pract 2016;116:279-287.

Sheikov N, McDannold N, Vykhodtseva N, Jolesz F, Hynynen K. Cellular mechanisms of the blood-brain barrier opening induced by ultrasound in presence of microbubbles. Ultrasound Med Biol 2004;30:979-989.

Skachkov I, Luan Y, van der Steen AFW, de Jong N, Kooiman K. Targeted microbubble mediated sonoporation of endothelial cells in vivo. IEEE Trans Ultrason Ferrelectr Freq Control 2014;61:1661-1667.

Simon RH, Ho SY, D'Arrigo JS, Wakefield AE, Hamilton SG. Lipid-coated ultrastable microbubbles as a contrast agent in neurosonography. Invest Radiol 1990;25:1300-1304.

Simon RH, Ho SY, Lange SC, Uphoff DF, D'Arrigo JS. Applications of lipid-coated microbubble ultrasonic contrast to tumor therapy. Ultrasound Med Biol 1993;19:123-125.

Simon RH, Ho SY, Perkins CR, D'Arrigo JS. Quantitative assessment of tumor enhancement by ultrastable lipid-coated microbubbles as a sonographic contrast agent. Invest Radiol 1992;27:29-34.

Simpson IA, Ponnuru P, Klinger ME. A novel model for brain iron uptake: introducing the concept of regulation. J Cereb Blood Flow Metab 2015;35:48-57.

Song GJ, Kim SM, Park KH, Kim J, Choi H, Cho KH. SR-BI mediates high density lipoprotein (HDL)-induced anti-inflammatory effect in macrophages. Biochem Biophys Res Comm 2015;457:112-118.

Sorop O, Olver TD, van de Wouw J, Heinonen I, van Duin RW, Duncker DJ, Merkus D. The microcirculation: a key player in obesity-associated cardiovascular disease. Cardiovasc Res 2017; doi:10.1093/cvr/cvx093 .

Srimanee A, Regberg J, Hallbrink M, Vajragupta O, Langel U. Role of scavenger receptors in peptide-based delivery of plasmid DNA across a blood-brain barrier model. Int J Pharm 2016;500:128-135.

Slot RE, Van Harten AC, Kester MI, JongbloedW, Bouwman FH, Teunissen CE, Scheltens P, Veerhuis R, van der Flier WM. Apolipoprotein A1 in cerebrospinal fluid and plasma and progression to Alzheimer's disease in non-demented elderly. J Alzheimers Dis 2017;56:687697.

Stukas S, Robert J, Wellington CL. High-density lipoproteins and cerebrovascular integrity in Alzheimer's disease. Cell Metab 2014;19:574-591. 
Sudduth TL, Weekman EM, Price BR, Gooch JL, Woolums A, Norris CM, Wilcock DM. Time-course of glial changes in the hyperhomocysteinemia model of vascular cognitive impairment and dementia (VCID). Neuroscience 2017;341:42-51.

Swaminathan SK, Ahlschwede KM, Sarma V, Curran GL, Omtri RS, Decklever T, Lowe VJ, Poduslo JF, Kandimalla KK. Insulin differentially affects the distribution kinetics of amyloid beta 40 and 42 in plasma and brain. $J$ Cereb Blood Flow Metab 2017; doi:10.1177/0271678X17709709 .

Tan XL, Xue YQ, Ma T, Wang X, Li JJ, Lan L, Malik KU, McDonald MP, Dopico AM, Liao FF. Partial eNOS deficiency causes spontaneous thrombotic cerebral infarction, amyloid angiopathy and cognitive impairment. Mol Neurodegener 2015;10:24.

Tarantini S, Tran CH, Gordon GR, Ungvari Z, Csiszar A. Impaired neurovascular coupling in aging and Alzheimer's disease: contribution of astrocyte dysfunction and endothelial impairment to cognitive decline. Exp Gerontol 2016;doi:10.1016/j.exger.2016.11.004 .

Tenreiro MM, Ferreira R, Bernardino L, Brito MA. Cellular response of the blood-brain barrier to injury: potential biomarkers and therapeutic targets for brain regeneration. Neurobiol Dis 2016;91:262-273.

Thanopoulou K, Fragkouli A, Stylianopoulou F, Georgopoulos S. Scavenger receptor class B type I (SR-BI) regulates perivascular macrophages and modifies amyloid pathology in an Alzheimer mouse model. Proc Natl Acad Sci USA 2010;107:20816-20821.

Timbie KF, Mead BP, Price RJ. Drug and gene delivery across the blood-brain barrier with focused ultrasound. J Control Rel 2015;219:61-75.

Toda N, Okamura T. Cigarette smoking impairs nitric oxide-mediated cerebral blood flow increase: implications for Alzheimer's disease. J Pharmacol Sci 2016;131:223-232.

Tong XK, Hamel E. Simvastatin restored vascular reactivity, endothelial function and reduced string vessel pathology in a mouse model of cerebrovascular disease. J Cereb Blood Flow Metab 2015;35:512-520.

Tonnies E, Trushina E. Oxidative stress, synaptic dysfunction, and Alzheimer's disease. J Alzheimer's Dis 2017; doi:10.3233/JAD-161088 .

Torrice M. Alzheimer's therapy goes acoustic. Chem Eng News 2015;93(\#11):5.

Toth P, Tarantini S, Csiszar A, Ungvari Z. Functional vascular contributions to cognitive impairment and dementia: mechanisms and consequences of cerebral autoregulatory dysfunction, endothelial impairment, and neurovascular uncoupling in aging. Am J Physiol Heart Circ Physiol 2017;312:H1-H20. 
Turner RS, Thomas RG, Craft S, van Dyck CH, Mintzer J, Reynolds BA, Brewer JB, Rissman RA, Raman R, Aisen PS. A randomized, placebo-controlled trial of resveratrol for Alzheimer disease. Neurology 2015;85:1383-1391.

Uiterwijk R, Huijts M, Staals J, Rouhl RP, De Leeuw PW, Kroon AA, Van Oostenbrugge RJ. Endothelial activation is associated with cognitive performance in patients with hypertension. Am J Hypertens 2016;29:464-469.

Vandal M, Alata W, Tremblay C, Rioux-Perreault C, Salem Jr N, Calon F, Plourde M. Reduction in DHA transport to the brain of mice expressing human ApoE4 compared to ApoE2. J Neurochem 2014;129:516-526.

van de Haar HJ, Jansen JFA, van Osch MJP, van Buchem MA, Muller M, Wong SM, Hofman PA, Burgmans S, Verhey FR, Backes WH. Neurovascular unit impairment in early Alzheimer's disease measured with magnetic resonance imaging. Neurobiol Aging 2016;45:190-196.

Vanhoutte PM, Shimokawa H, Feletou M, Tang EH. Endothelial dysfunction and vascular disease - a 30th anniversary update. Acta Physiol (Oxf) 2017;219:22-96.

van Rooij T, Skachkov I, Beekers I, Lattwein KR, Voorneveld JD, Kokhuis TJ, Bera D, Luan Y, van der Steen AF, de Jong N, Kooiman K. Viability of endothelial cells after ultrasoundmediated sonoporation: influence of targeting, oscillation, and displacement of microbubbles. J Control Rel 2016;238:197-211.

Velagapudi S, Yalcinkaya M, Piemontese A, Meier R, Norrelykke SF, PerisaD, Rzepiela A, Stebler M, Stoma S, Zanoni P, Rohrer L, von Eckardstein A. VEGF-A regulates cellular localization of SR-BI as well as tansendothelial transport of HDL but not LDL. Arterioscler Thromb Vasc Biol 2017;37:794-803.

Vishnyakova TG, Bocharov AV, Baranova IN, Chen Z, Remaley AT, Csako G, Eggerman TL, Patterson AP. Binding and internalization of lipopolysaccharide by CLA-1, a human orthologue of rodent scavenger receptor B1. J Biol Chem 2003;278:22771-22780.

Wakefield AE, Ho SY, Li XG, D'Arrigo JS, Simon RH. The use of lipid-coated microbubbles as a delivery agent for $7 \beta$-hydroxycholesterol to a radiofrequency lesion in the rat brain. Neurosurgery 1998;42:592-598.

Walker R, Decker EA, McClements DJ. Development of food-grade nanoemulsions and emulsions for delivery of omega-3 fatty acids: opportunities and obstacles in the food industry. Food Funct 2015;6:42-55.

Wan L, Nie G, Zhang J, Luo Y, Zhang P, Zhang Z, Zhao B. B-Amyloid peptide increases levels of iron content and oxidative stress in human cell and Caenorhabditis elegans models of Alzheimer disease. Free Radic Biol Med 2011;50:122-129. 
Wang F. Vascular dysfunction associated with type 2 diabetes and Alzheimer's disease: a potential etiological linkage. Med Sci Monit Basic Res 2014;20:118-129.

Wang F, Zou Z, Gong Y, Yuan D, Chen X, Sun T. Regulation of human brain microvascular endothelial cell adhesion and barrier functions by memantine. J Mol Neurosci 2017;62:123129.

Wang YJ. Lessons from immunotherapy for Alzheimer's disease. Nat Rev Neurol 2014;10:188-189.

Wang GH, Jiang ZL, Li YC, Li X, Shi H, Gao YQ, Vosler PS, Chen J. Free-radicle scavenger Edaravone treatment confers neuroprotection against traumatic brain injury in rats. $\mathrm{J}$ Neurotrauma 2011;28:2123-2134.

Wang L, Du Y, Wang K, Xu G, Luo S, He G. Chronic cerebral hypoperfusion induces memory deficits and facilitates $A \beta$ generation in C57BL/6J mice. Exp Neurol 2016;283(Pt.A):353-364.

Wang P, Wu Q, Wu W, Li H, Guo Y, Yu P, Gao G, Shi Z, Zhao B, Chang YZ. Mitochondrial ferritin deletion exacerbates $ß$-amyloid-induced neurotoxicity in mice. Oxid Med Cell Longev 2017; doi:10.1155/2017/1020357.

Weekman EM, Sudduth TL, Caverly CN, Kopper TJ, Phillips OW, Powell DK, Wilcock DM. Reduced efficacy of anti-Aß immunotherapy in a mouse model of amyloid deposition and vascular cognitive impairment comorbidity. J Neurosci 2016;36:9896-9907.

Williams JJ, Mayurasakorn K, Vannucci SJ, Mastropietro C, Bazan NG, Ten VS, Deckelbaum RJ. N-3 fatty acid rich triglyceride emulsions are neuroprotective after cerebral hypoxic-ischemic injury in neonatal mice. PLoS One 2013;8:e56233.

Winkler EA, Nishida Y, Sagare AP, Rege SV, Bell RD, Perlmutter D, Sengillo JD, Hillman S, Kong P, Nelson AR, Sullivan JS, Zhao Z, Meiselman HJ, Wenby RB, Soto J, Abel ED, Makshanoff J, Zuniga E, DeVivo DC, Zlokovic BV. GLUT1 reductions exacerbate Alzheimer's disease vasculo-neuronal dysfunction and degeneration. Nat Neurosci 2015;18:521-533.

Wu KW, Kou ZW, Mo JL, Deng XX, Sun FY. Neurovascular coupling protects neurons against hypoxic injury via inhibition of potassium currents by generation of nitric oxide in direct neuron and endothelium cocultures. Neuroscience 2016;334:275-282.

Xie F, Boska MD, Lof J, Uberti MG, Tsutsui JM, Porter TR. Effects of transcranial ultrasound and intravenous microbubbles on blood brain barrier permeability in a large animal model. Ultrasound Med Biol 2008;34:2028-2034. 
Yang R, Wang Q, Li F, Li J, Liu X. Edaravone injection ameliorates cognitive deficits in rat model of Alzheimer's disease. Neurol Sci 2015;36:2067-2072.

Yassine HN, Feng Q, Azizkhanian I, Rawat V, Castor K, Fonteh AN, Harrington MG, Zheng L, Reed BR, DeCarli C, Jagust WJ, Chui HC. Association of serum docosahexaenoic acid with cerebral amyloidosis. JAMA Neurology 2016a;doi:10.1001/jamaneurol.2016.1924.

Yassine HN, Rawat V, Mack WJ, Quinn JF, Yurko-MauroK, Bailey-Hall E, Aisen PS, Chui HC, Schneider LS. The effect of ApoE genotype on the delivery of DHA to cerebrospinal fluid in Alzheimer's disease. Alzheimer's Res Ther 2016b;8:25-34.

Yin ZG, Li L, Cui M, Zhou SM, Yu MM, Zhou HD. Inverse relationship between apolipoprotein A-I and cerebral white matter lesions: a cross-sectional study in middle-aged and elderly subjects. PLoS One 2014;9:e97113.

Yoon CY, Steffen LM, Gross MD, Launer LJ, Odegaard A, Reiner A, Sanchez O, Yaffe K, Sidney S, Jacobs Jr DR. Circulating cellular adhesion molecules and cognitive function: the coronary artery risk development in young adults study. Front Cardiovasc Med 2017; doi:10.3389/fcvm.2017.00037 .

Zenaro E, Piacentino G, Constantin G. The blood-brain barrier in Alzheimer's disease. Neurobiol Dis 2016;doi:10.1016/j.nbd.2016.07.007 .

Zhao HF, Li N, Wang Q, Cheng XJ, Li XM, Liu TT. Resveratrol decreases the insoluble Aß1-42 level in hippocampus and protects the integrity of the blood-brain barrier in AD rats. Neuroscience 2015;310:641-649.

Zhu J, Song W, Li L, Fan X. Endothelial nitric oxide synthase: a potential therapeutic target for cerebrovascular diseases. Molecular Brain 2016;9:30. 